\title{
ACKNOWLEDGING NON-HUMAN PERSONS: RECONSTITUTING OUR CONCEPTION OF PERSONHOOD
}

\author{
by \\ Rebecca Kovacs \\ Bachelor of Arts, King's University College at Western University, London, Ontario, Canada, \\ 2012.
}

\author{
A thesis \\ presented to Ryerson University \\ in partial fulfillment of the \\ requirements for the degree of \\ Master of Arts \\ in the program of \\ Philosophy
}

Toronto, Ontario, Canada, 2017

(C) Rebecca Kovacs 2017 


\section{AUTHOR'S DECLARATION FOR ELECTRONIC SUBMISSION OF A THESIS}

I hereby declare that I am the sole author of this thesis. This is a true copy of the thesis, including any required final revisions, as accepted by my examiners.

I authorize Ryerson University to lend this thesis to other institutions or individuals for the purpose of scholarly research.

I further authorize Ryerson University to reproduce this thesis by photocopying or by other means, in total or in part, at the request of other institutions or individuals for the purpose of scholarly research.

I understand that my thesis may be made electronically available to the public. 


\begin{abstract}
Acknowledging Non-Human Persons: Reconstituting Our Conception of Personhood

Rebecca Kovacs
\end{abstract}

Master of Arts in Philosophy, Ryerson University, 2017

This thesis seeks to reconstitute our conventional conceptions of personhood, and open this privileged status to many non-human animals. I begin with a discussion of the concept of personhood and some of the intricacies of the classification process. Many conventional conceptions require "higher" functions, like language and rationality, for personhood. In Chapter Two I challenge such views. Chapter Three articulates and defends my own conception of personhood. I define persons as those who can directly and personally be harmed. Such beings are subjects with emotions and interests. I discuss evidence that many non-human animals possess these characteristics and, as such, should be classified as persons. In Chapter Four I explore the practical application of my conception and potential policy implications, focusing on issues around the confinement of non-human animal persons in zoos and aquariums. 


\section{Acknowledgements}

I give my thanks to my advisor, Dr. Alex Wellington, for her continuing belief in me and her assistance in taking my scholarship to the next level. Thank-you to my examining committee, Dr. Robert Murray and Dr. Elizabeth Trott, for their helpful feedback. Thank-you to my husband, Matt Belford, for his support and understanding. And thank-you to Gabriel Fillion, for being a catalyst in my journey.

This research was supported by the Social Sciences and Humanities Research Council of Canada. 


\section{Dedication}

This thesis is dedicated to the non-human animal companions I've had the pleasure of living with, especially my current cat companions, Sophia and Tiberius, who continually remind me who I'm working for. 


\section{Contents}

Introduction

Some Historical Themes in the Evolution of Thought about Non-Human Animals 4 Summary of Contents 11

Chapter 1: The Concept of Personhood 14

The Differing Senses of the Term "Person" 15

$\begin{array}{ll}\text { Classifying Persons } & 20\end{array}$

Chapter 2: Challenging the Moral Relevance of Language and Rationality 28

$\begin{array}{ll}\text { Language } & 30\end{array}$

Rationality 36

Chapter 3: The Characteristics of Persons 42

$\begin{array}{ll}\text { Subjectivity } & 43\end{array}$

Emotions $\quad 66$

$\begin{array}{ll}\text { Interests } & 68\end{array}$

Advantages of my Account of Personhood 71

Chapter 4: Practical Application and Policy Implications 74

Moral and Legal Obligations to Non-Human Animal Persons 75

The Lives of Captive Non-Human Animal Persons 88

Challenging the Justifications for Zoological Institutions 105

Authenticity and Objectification in Zoological Institutions 109

$\begin{array}{ll}\text { Concluding Remarks } & 112\end{array}$

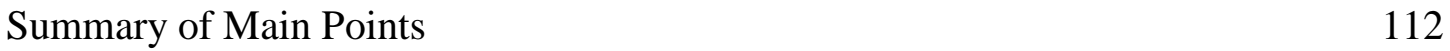

$\begin{array}{ll}\text { Moving Forward } & 114\end{array}$

$\begin{array}{ll}\text { Appendix } & 118\end{array}$

$\begin{array}{ll}\text { Bibliography } & 121\end{array}$ 
Introduction

The motivation for this thesis began with a desire to give non-human animals a voice and to change the way we think about and interact with them. An immediate difficultly faced by anyone wanting to improve our ambivalent relationship with non-human animals is the challenge of figuring out what we have been mistaken about and which of many options may be the best way forward. One of the factors that has led to such an ambivalent relationship with non-human animals is the fact that we have fundamentally misunderstood them in the past and, as such, have accorded them an inappropriate moral status. I believe that starting from the foundation, with our ideas about the abilities and natures of non-human animals, is where we need to begin.

This thesis approaches its investigation of non-human animals from a philosophical, and specifically ethical perspective. It focuses on arguing for a change in the moral status of many non-human animals, drawing upon some of the latest scientific findings and philosophical thought. The moral status that I believe is appropriate for many non-human animals is that of "persons."

To be a "person" or have "personhood" in the normative, philosophical sense of the term is to be the kind of being who is worthy of special moral consideration. In our society, persons, whether natural or artificial, are recognized as having the highest moral status possible and are the only beings who are protected by legal rights. ${ }^{1}$ In addition to arguing that many non-human animals should be classified as persons, I also argue for and defend my own conception of personhood, which varies slightly from traditional philosophical conceptions. I define persons as

1 Hereafter, unless specified otherwise, when I use the term "person" or refer to the "personhood" of certain beings, I am referring to natural persons. 
those who can be directly or personally harmed. ${ }^{2}$ Such beings are subjects who have emotions and interests.

Non-human animal persons should have rights in much the same way that human persons do. Should such a change in their moral and legal status occur, we would become ethically and legally obligated to change many of our conventional practices. Most of the ways in which we use non-human animals requires their confinement, such as on farms and in labs, circuses, and zoos. It is beyond the scope of this thesis to analyze every way in which we use non-human animals, so I will focus on the problems with confining non-human animal persons in an attempt to undermine multiple kinds of practices at once.

Before providing a detailed outline of this thesis, I would first like to situate my position within the historical narrative surrounding our beliefs about non-human animals. The idea that some non-human animals could be persons and could have rights is at the forefront of an ethical, historical progression that can be seen evolving over time. There are three main themes that I will highlight - ones that become apparent when we take a historical look at our relationship with non-human animals. The first theme is that there has been a move from a mystical or religious understanding of non-human animals to a more secular and scientific understanding. In antiquity, we find an understanding of non-human animals that derives mostly from ultimate (holy) authority. In modernity, we find more cases where non-human animals are examined objectively and scientifically, both theoretically and through medical experimentation.

2 I use the term "harm" in a broad sense, to refer to many different ways in which a person can be harmed. This can include mental, or psychological distress, physical discomfort, pain, emotional distress, and perhaps more. 
The second theme is that there has historically been an insistence upon there being fundamental differences between humans and non-human animals, and that this gap (the perceived differences) has been closing. In ancient Greek thought, we find the characteristics of humans and non-human animals contrasted radically, and an impetus was developing to not fall prey to one's own animality. Today, thanks to the growing findings from the scientific study of all animals (humans and non-humans), we know that there are more similarities between many species than there are differences. ${ }^{3}$

The third and last theme, which I believe to be an emergent property of the movements seen in theme one and two, is that the perceived moral significance of non-human animals has grown. In antiquity, non-human animals were generally thought to be outside the realm of justice; they had no formal legal protection for their welfare or interests. Beginning in modernity, we see the first true non-human animal welfare laws. Today, we find many theorists arguing for the personhood of non-human animals, for an improvement in both the quality and coverage of their legal protection, and for dramatic changes in human conduct in relation to non-human animals.

These three themes are inter-related and reflect a consistent trend towards a progression in our beliefs and practices. In the following brief investigation of history, I will be limiting discussion to only those cultures or philosophers who were influential in shaping the modern

3 For further discussion, see Jonathan Marks, What it Means to be $98 \%$ Chimpanzee: Apes, People, and Their Genes. 
Western view of non-human animals, and to those works or ideas that highlight the three themes listed above. ${ }^{4}$

\section{Some Historical Themes in the Evolution of Thought about Non-Human Animals}

There were not nearly as many thinkers interested in the study of non-human animals in antiquity compared to the present. In antiquity, there were a few thorough investigations of the nature of non-human animals and how we should treat them that are notable, such as Aristotle's well known work De Motu Animalium, which is about the principles of animal locomotion. A work by Porphyry entitled On Abstinence from Killing Animals presents arguments for and against the instrumental use of animals for human purposes.

Ancient Greek texts often featured comparisons of humans to non-human animals and used the behaviour of non-human animals as metaphors for, or examples of, undesirable behaviour. For example, to claim a man was acting like an animal was to insinuate he was being beastly, irrational, or mindless. To give in to certain feelings or behavior was to give in to the animal in us, which was dangerous and needed to be controlled. Anyone acting "like animals" or anyone who idolized or protected them were considered weak and misguided. In the words of the Stoic moralist, Epictetus (A.D. 55-135):

What is a man? The answer is: "A rational and mortal being." Then, by the rational faculty, from whom are we separated? From wild beasts. And from what others? From sheep and like animals. Take care then to do nothing like a wild beast; but if you do, you have lost the character of a man; you have not fulfilled your promise. See that you do nothing like a sheep; but if you do, in this case the

4 I acknowledge that there are many other themes that may be present in the evolution of thought about non-human animals, and that I leave out a lot of significant thinkers and works. A more thorough examination of these themes could be taken up in another project. 
man is lost. What then do we do as sheep? When we act gluttonously, when we act lewdly, when we act rashly, filthily, inconsiderately, to what have we declined? To sheep. What have we lost? The rational faculty. When we act contentiously and harmfully and passionately, and violently, to what have we declined? To wild beasts. ${ }^{5}$

The Stoics and Epicureans did not think ethical questions about justice were relevant to our relations with non-human animals since it was believed that non-human animals could not act with justice and were not part of the moral realm. A practical reason for conceiving of nonhuman animals as inferior and outside the realm of justice is that it could justify sacrificing them, rather than humans, to the Gods. Interestingly, some non-human animals, those considered sacred, could not be treated with cruelty, but could be killed if under the guise of sacrifice. ${ }^{6}$

In general, the ancient Greeks believed that our souls were separate from our bodies, and that the soul was immortal and rational while the body was emotional and temporary. They believed that animal souls differed from human souls in that they lacked the intellectual and rational components. This is seen throughout Plato's works. Aristotle's notion of a "chain of being" also suggested a hierarchy based on characteristics believed to be possessed by various types of creatures. At the top of the chain of being were gods, who were superior to humans. Inferior to humans were non-human animals, and inferior to non-human animals were plants. A version of this kind of hierarchical belief system was (and to some extent still is) present as a feature of social life, with white, privileged men being considered superior to non-white people, women, children, and non-human animals. Such a hierarchy justified the differential, lesser treatment of "inferior" individuals. Early Christian thought also supported this idea of a chain of

\section{Epictetus, Discourses 2.9.}

6 Stephen R. L. Clark, "Animals in Classical and Late Antique Philosophy,” in The Oxford Handbook of Animal Ethics, ed. Tom L. Beauchamp and R. G. Frey, 35-60 (New York: Oxford University Press, 2011), 39. 
being and characterized non-human animals as existing for the benefit of humans and as things to be used for our purposes. ${ }^{7}$

In addition to the philosophical writings that come out of antiquity, we can also look to what people did as a matter of practice to give us insight into how they regarded (and treated) non-human animals. In ancient Greece and Rome, non-human animals were used for many purposes, including agriculture (such as oxen pulling carts), as cavalry in war, for food, to sacrifice to gods, companionship, to be hunted themselves or assist in the hunting of other nonhuman animals, and, as in the height of the Roman Empire, to be dramatically slaughtered for entertainment. It is believed that the practice of slaughtering and fighting non-human animals in the gladiator arenas was done as a demonstration of the power and dominance of the Roman people. Keeping live exotic non-human animals and having the carcasses of rare slayed nonhuman animals stuffed and put on display in the home also affirmed this "natural" dominance and hierarchy. ${ }^{8}$

The surviving documents and stories of ancient Greece and Rome have formed the backbone of Western philosophy and have somewhat continued to shape how we see ourselves and others. In modernity, we see many of the same beliefs persisting, such as a pride in being different from non-human animals, the view that white people are superior to other races, and that women are inferior to men. ${ }^{9}$ Thus, the story of the beginning of modernity bears many

7 Clark, "Animals in Classical and Late Antique Philosophy," 36.

8 Dale Jamieson, “Against Zoos," in In Defense of Animals, ed. Peter Singer, 39- 50 (New York: Basil Blackwell, 1985), 40.

9 For literature discussing the relationships between race, sex, gender, and non-human animals, see Adams, The Sexual Politics of Meat: A Feminist-Vegetarian Critical Theory. 
similarities to antiquity, but one (among other) major advancements, the invention of precision tools and scientific inquiry, began to set these periods apart.

Early modernity was the birthplace of the first ever systematized medical experiments. During the infancy of formal medical experimentation, there seemed to be absolutely no restrictions on what experiments could and could not be done on non-human animals. For instance, the Royal Society in the U.K. in the 1660's experimented on dogs, observing their reactions to poisons, seeing how long the dog could survive after inflicting severe physical trauma, and testing the compatibility of using multiple species' blood for transfusions. Not to experiment on non-human animals, or to demonstrate dislike or disgust for the practice was viewed as weak, squeamish and effeminate. ${ }^{10}$

The practices of the Royal Society in the 1600's tells us a lot about the (lack of) regulation of non-human animal use and suggests that people at this time were not yet taking the interests of non-human animals seriously (if they thought they had interests at all). In the $18^{\text {th }}$ and $19^{\text {th }}$ centuries, we begin to see a change in thinking about the moral status of non-human animals. Two figures from this time that are often mentioned in contemporary animal ethics literature are Immanuel Kant and Jeremey Bentham. Their ideas about non-human animals are very different, yet both views have been taken up and worked with by well-known contemporary philosophers who write about the moral standing of non-human animals such as Christine Korsgaard and Peter Singer.

10 Aaron Garrett, "Animals and Ethics in the History of Modern Philosophy," in The Oxford Handbook of Animal Ethics, ed. Tom L. Beauchamp and R. G. Frey, 61-87 (New York: Oxford University Press, 2011), 63. 
Christine Korsgaard discusses what a Kantian perspective on animal ethics would entail in her article, "Interacting with Animals: A Kantian Account."11 Kant claims that we only have duties to humans but not to non-human animals, although we may have duties regarding them. This is to say that we owe nothing directly to non-human animals - they are not the kind of things that are worthy of moral consideration. In addition, we cannot have obligations towards non-human animals because we are not in a reciprocal relationship with them and they lack rationality. ${ }^{12}$ Yet, we should not behave however we want to towards non-human animals either. Kant believed that treating non-human animals with cruelty manifests a bad character and could lead to treating humans with cruelty. While humans should be treated as ends rather than as means to an end and are persons, non-human animals are not ends in themselves and are merely things. So, for the sake of other humans, we should not treat non-human animals with malice or cruelty and should have some limits of conduct towards them. ${ }^{13}$

While Kant's view would offer little as a strong justification for the protection of nonhuman animals, he does suggest there should be some "standards" for how we treat them. In contrast to Kant's perspective, which is anthropocentric, is that of Jeremy Bentham. A famous footnote in the introduction of Bentham's Principles of Morals and Legislation (published 1789) reflects an evolving attitude in the arena of ethical thinking. Here, we see an acknowledgment of the significance of a non-human animal's own experience and point of view:

11 Christine M. Korsgaard, "Interacting with Animals: A Kantian Account," in The Oxford Handbook of Animal Ethics, ed. Tom L. Beauchamp and R. G. Frey, 91-118 (New York: Oxford University Press, 2011).

12 Korsgaard, "Interacting with Animals," 93.

13 Ibid., 99-100. 
The French have already discovered that the blackness of the skin is no reason why a human being should be abandoned without redress to the caprice of a tormentor. It may come one day to be recognized, that the number of the legs, the villosity of the skin, or the termination of the os sacrum, are reasons equally insufficient for abandoning a sensitive being to the same fate. What else is it that should trace the insuperable line? Is it the faculty of reason, or, perhaps, the faculty of discourse? But a full grown horse or dog, is beyond comparison a more rational, as well as a more conversible animal, than an infant of a day, or a week, or even a month, old. But suppose the case were otherwise, what would it avail? The question is not, Can they reason? nor, Can they talk? but, Can they suffer? ${ }^{14}$

A lot of literature in the animal ethics field refer to this specific passage, and for good reason. It represents an important change in perspective about the moral significance of non-human animals and was relied upon for support for the development of the first modern non-human animal welfare laws. ${ }^{15}$ Starting in the early 1800 's we begin to see policy arising around non-human animal use that actually carried punishment for violators. Martin's Act in 1822 (Britain) created fines for those who harmed domesticated cattle unnecessarily. The Cruelty to Animals Act in 1835 (Britain) clarified and furthered this act to define cattle as including dogs, sheep, bears, bulls, and to also ban bear-baiting and cockfighting. ${ }^{16}$

The last major influence in the evolution of moral thinking about non-human animals (to be discussed here) is the release of Peter Singer's book, “Animal Liberation" in 1975. Reading this text one can detect the influence of Bentham's suggestion that the ability to suffer is morally significant. In Animal Liberation, Singer discusses speciesism, the ways in which humans and

14 Jeremy Bentham, An Introduction to the Principles of Morals and Legislation, Ed. J.H. Burns and H.L.A. Hart (Oxford: Oxford University Press, 1982), chap 17, §1,4, note.

15 For an informative and critical analysis of Bentham's thoughts about non-human animals and a comparison with modern thinker Peter Singer, see Gary Francione, Introduction to Animal Rights: Your Child or the Dog?

16 Garrett, “Animals and Ethics,” 80. 
non-human animals may be equal, the value and weight of the interests of non-human animals, and vegetarianism. Singer takes a utilitarian stance and argues that non-human animals' interests matter morally and should be considered in ethical deliberation. Utilitarians are concerned with the promotion of happiness, pleasure, and the satisfaction of one's interests and the avoidance of pain, suffering, and interest frustration. (In chapter four I will discuss why a utilitarian view like Singer's is not as compatible with a personhood approach as a deontological view).

Animal Liberation influenced not only the academic field of animal ethics but also became part of popular literature as well. Singer is often referred to as the father of the modern animal rights movement and his publication has undoubtedly fueled and advanced the field. The practical nature of Singer's account was also a warm welcome as it contrasted with his contemporaries who, for the most part, were much less applied in nature. His work was also innovative because of its focus on sentience and suffering. For Singer, sentience (the ability to feel pleasure and pain) and the capacity for suffering is what makes a being morally considerable and, as such, they deserve to have their interests considered in ethical deliberation.

In sum, the present academic study of animal ethics can still reflect lingering tensions and presumptions seen since antiquity. However, we see a closing of the gap between the perceived differences of humans and non-human animals, a trend towards a more objective approach to understanding non-human animals, and an increasing number of individuals who are fighting for a change in the moral status or significance of non-human animals.

The scientific study of both humans and non-human animals has acted like a sword to strongly defend newer ideologies and has given philosophers new data to work with to revise moral theories and theories of mind (should they acknowledge it). This thesis works with the 
information we have gathered from biology and psychology to analyse the nature of certain mental characteristics and their relevance to making a creature the kind of being who should be worthy of special moral consideration.

Throughout this thesis, I will claim that many non-human animals are persons, I will reconstitute our conception of personhood, and challenge the ethicality of confining non-human animal persons. In doing so, this thesis lies at the most progressive end of this ethical, historical evolution. A detailed outline of the contents of this thesis and an explanation of method follows.

\section{Summary of Contents}

The first chapter of this thesis discusses the concept of personhood generally. Here I will distinguish between the physical, metaphysical, moral, and legal senses of the term "person," and explain why my conception of personhood is a metaphysical one with normative implications. I will then discuss how to classify persons, touching on issues of identity and time, such as how the characteristics required for personhood are not always present in the same individual, and how we may deal with exceptional cases. This chapter concludes with a discussion of the work of Eva Feder Kittay and Mary Anne Warren, who have very different views about what makes an individual morally considerable.

The second chapter of this thesis challenges the inclusion of language and rationality as requirements for personhood. I believe these criteria are too demanding and set the threshold for personhood status unnecessarily and unjustifiably high. I will criticize what I call "exclusive" positions, which claim that language is required for rationality and that possessing rationality is required to be an object of moral concern. An implication of this view is that non-human animals 
are not objects of moral concern. Here, I will discuss the nature of language and rationality, how the presence of degrees of language ability and rationality in non-human animals may present a problem for the exclusive position, and distinguish between the characteristics required to partake in moral decision making and be a moral agent versus the characteristics required to be morally considerable.

The third chapter of this thesis articulates my conception of personhood. I define persons as those who can be personally or directly harmed. Such beings are subjects who have emotions and interests. Many non-human animals are subjects and have emotions and interests. They can be harmed in ways that affect them directly; there is someone that can be hurt rather than something. Therefore, many non-human animals are persons. ${ }^{17}$

To defend this position, I will define subjectivity, emotions, and interests and their relevance to my definition. In short, I claim that to have subjective experiences, one must be conscious, self-aware, and have some degree of psychological unity (to have a connection between mental states that allows for a continuous experience). To be capable of emotions (such as anxiety, fear, and contentment) is to have a perspective on one's experiences, and is what makes an experience positive or negative rather than one of indifference. Having interests (such as the interests in finding food and staying alive) is essential for determining which actions harm

17 When I use the term "non-human animals" throughout this thesis, I do mean to refer to all those in the animal kingdom who are not human. However, the literature in the field of animal ethics tends to focus strongly on vertebrates (mammals, fish, birds, reptiles, and amphibians) in their discussions, particularly mammals and birds. As such, my discussions will also refer mostly to this particular class of animals. But this is not to suggest that non-human animals from other taxonomic categories are not candidates for personhood. Perhaps vertebrates, and mammals and birds in particular, are simply more like humans than other classes of animals, and as such they have been chosen as the most relatable examples. 
persons and which do not, since the frustration of interests can have negative effects on one's health, cause suffering, and be un-dignifying.

The fourth and final chapter of this thesis examines the implications of my conception of personhood and how it may be applied. I begin by considering the moral relevance of our relationship to different groups of non-human animals, distinguishing between domestic, liminal, and wild groups. I will suggest that we have moral and legal obligations to non-human animal persons that differs depending on our relationship. Across all cases I suggest that a rights approach that focuses on the importance of interests is necessary to ensure non-human animal persons are treated well and are able to flourish.

The last part of chapter four focuses on issues with confining non-human animal persons. I will be focusing particularly on zoos and aquariums since they are typically thought to provide the best captive conditions possible compared to other practices (such as in factory farms, circuses, and labs). Thus, if it can be shown that confinement here is problematic, my conclusion can be extended to other practices that clearly provide less adequate conditions. In my discussion of confinement, the themes of interest frustration, liberty, autonomy, integrity, dignity, and health will surface as concepts that are incredibly useful for illuminating practices that harm nonhuman animal persons. Lastly, the justifications for and supposed benefits of zoological institutions will be challenged, and I will briefly address issues regarding authenticity and objectification in the zoo experience. 


\section{Chapter 1}

The Concept of Personhood

In everyday speech when someone uses the word "person" they are usually referring to a human being. Consider the following phrases: "You need to pick up the documents in person"; "The van seats 7 people"; "That politician is a man of the people." All of these colloquial uses of the term "person" refer to an individual or group of human beings. However, formally, the term "person" and the term "human" are conceptually distinct and consist of different classification criteria. Depending on the definition of personhood one looks to, the boundaries of the term "person" can sometimes include non-human animals and can sometimes exclude some humans. ${ }^{18}$ But across all contexts, at its roots, when we seek to find persons we are seeking to find beings worthy of special moral consideration.

Persons are those who have the highest moral status possible and they are also accorded legal rights. Intuitively and conceptually, the categorization of a being as a person implies that they are a "who" rather than a thing. As a "who" rather than a thing, they are subjects rather than objects and as such can invoke moral obligation. The kinds of beings I believe are persons are those who can be personally or directly harmed. The necessary conditions for being this kind of being is that one is a subject and has subjective experiences, one has emotions, and one has interests. Such beings are moral recipients (but not necessarily moral agents) and can experience the harm being done to them.

18 For example, see Mary Anne Warren's article, "On the Moral and Legal Status of Abortion," and Sarah Chan and John Harris’s article, "Human Animals and Nonhuman Persons." 
Before getting into a deep discussion of my conception of persons, which will be the focus of chapter three, we need to get a better idea of how to work with the notion of personhood and set out some parameters. I will begin this chapter with a discussion of the various senses of the term "person" and how I intend to use the term. In the next section, I will discuss the interrelatedness of mental capacities, how personhood is actually a transient status, how to determine the status of an entire species and of exceptional individuals, and what kinds of characteristics we should be concerned with.

\section{The Differing Senses of the Term "Person"}

Determining what constitutes personhood isn't a simple matter. To complicate things from the outset, there are at least four different senses of the term "person" that can overlap: The physical, metaphysical, moral, and legal. The physical sense of the term is implicit (and assumed) in my analysis. The metaphysical sense of the term is the sense which is discussed at length throughout chapters one to three. The moral sense of the term is relevant to chapter four where I discuss our moral obligations to non-human animal persons. And finally, the legal sense of the term, while not directly relevant to this thesis, may be indirectly relevant to chapter four when I discuss our potential legal obligations to non-human animal persons. Let us now get a sense of how these uses of the term "person" differ.

In the physical sense, a being is a person if they have a physical presence, such as a living, animate body. Quite simply, it is the state of existing in a physical form. Physical personhood refers strictly to what is physical rather than metaphysical - I.e. It does not refer to or include in its definition things such as the existence of a soul, the mind, or spirit. The ancient 
question of what kind of material we are made of is relevant here. Some mind-body dualists (those who believe the body is a separate thing that is made up of something different from the mind or soul) believe that having a mind or soul is an attribute unique to persons. In opposition to the mind-body dualists, physicalists believe that there is nothing more to living creatures than physical matter. If a thinker believes that the existence of a non-physical soul is essential for personhood, then the burden of proof rests on them to demonstrate its likely existence and why it is morally relevant. ${ }^{19}$

Metaphysical personhood is the most commonly used sense of "person" in both the human and the non-human animal context, and is the sense that I will be working with the most. To be a metaphysical person, as the name somewhat suggests, is to be the kind of being that fits into a particular group or category, whose membership is determined by whether or not certain traits are possessed. Traits commonly believed to be relevant to metaphysical personhood include the existence of memory, self-awareness, the capacity to feel pain and pleasure, the capacity to form social bonds, and the ability to use language, among many others. The inclusion, exclusion, and classification of characteristics as necessary or sufficient for personhood varies from account to account.

Using the term "metaphysical" to describe membership in a particular group is slightly different from the usual use of the term in philosophy. Typically, metaphysical topics in philosophy include the study of space, time, causation, continuance, freedom, determinism, and

19 The possibility of the existence of things like souls and their role in making someone truly a person will not be addressed in this thesis since it is beyond the scope. I do not feel it is necessary to discuss this topic since determining who is a person based on other knowable characteristics is fruitful and sufficient. The conception of personhood that I will articulate should be compatible with views that require a soul for personhood, although my view does not require it. 
the mind-body problem, among others. To talk about persons in a metaphysical sense is to capture a part of these topics as they relate to the life and being of living things. Attributes like being an autonomous agent, not being determined wholly by one's environment, having a continuous mental experience, being rational, being self-aware, and having a sense of time, among other phenomenon, are often believed to be traits of persons. ${ }^{20}$

Other than the fact that metaphysical conceptions of personhood are increasing in popularity, there are two additional reasons that I have chosen to work with a metaphysical (rather than strictly moral) conception of personhood. First, I believe that there is a lot of misunderstanding about the nature and abilities of many non-human animals and that it is important to correct our outdated ideas. A metaphysical conception of (non-human animal) personhood allows for this since we must define the characteristics required to fit this classification.

Second, since metaphysical conceptions usually comprise a list of required mental capacities, we can look to the most recent findings of science for evidence of the existence of the capacities in question. This is to say that we can actually empirically verify whether or not a creature possesses these characteristics. Researchers now have a good idea of what indications to look for that suggest the existence of various mental capacities in non-human animals, or they are at least able to make an approximation of their abilities. (More will be said about which

20 It is beyond the scope of this thesis to discuss in detail all the metaphysical elements of personhood. For an on-going discussion about the intersections of metaphysics, personhood, non-human animals, and exceptional individuals, see Shelly Kagan's 2016 article, "What's Wrong with Speciesism?" Kagan's article is featured in the Journal of Applied Philosophy, alongside three responses from notable philosophers in the field of animal ethics: David DeGrazia, Jeff McMahan and Peter Singer. 
behaviours indicate the existence of certain mental capacities in chapters two and three). This is a notable strength, since it makes the application of such conceptions of personhood easier, which is what I intend to discuss in chapter four.

While moral agency is sometimes a requirement for metaphysical personhood, it is sometimes analyzed separately as a basis for an alternative conception of personhood. In the strictly moral sense of the term, person, a being is considered a person if they are a moral agent. A moral agent is someone who can be held accountable for their actions and their behaviour can legitimately be classified as right or wrong. Moral agents have the capacity to act with intention and have an awareness or knowledge of consequences. It is generally assumed that most humans are moral agents and non-human animals are not. This assumption is based on the idea that nonhuman animals either do not act with intention, and/or they don't fully realize the impact of their actions on others. For example, most of us would think it is wrong if our friend ripped open and ruined our furniture. We would blame them for their actions and possibly ask them to help pay for a replacement. But most of us would not judge our cat companion the same way, even though they too can ruin our furniture after years of sharpening their claws on it. Most of us would say that the cat is not blameworthy in the same kind of way that our friend is, even though their actions have led to the same outcome. In this situation, we must ask whether the cat really intended to ruin the furniture, whether they fully understood the damage they could inflict, and whether they understood that it would be costly and inconvenient for you to replace. ${ }^{21}$

21 And of course, one must ask themselves whether they have provided an adequate environment for their cat companion and took the time and effort to work with the cat to re-direct this natural behaviour towards an alternative object like a scratching post. 
The cat in this example does not seem totally blameworthy since it is unlikely they had a full understanding of the significance of their actions. However, it does not follow that they are completely outcast from the moral realm, nor does it mean they could not be a person. Although a non-human animal such as a cat may not be a moral agent, they can still be the kind of the being that can be harmed. The term "moral recipient" applies to those beings that can be harmed by the actions of moral agents but are not themselves moral agents. Thus, moral agents are also moral recipients, but not all moral recipients may be moral agents. If a definition of personhood requires the possession of moral agency in this sense, then most non-human animals, young human children, and severely mentally ill or cognitively disabled human adults may not be considered persons.

Lastly, the legal sense of the term "person" typically refers to an individual human being or, controversially, to a corporation. Many corporations interact with their clients and other corporations in the same way humans interact with each other. Based on this analogy, we hold corporations accountable for their actions as we do individual humans. Understanding and treating corporations like human persons can be useful for determining legalities and responsibilities. Likewise, metaphysical personhood can carry moral and legal implications. I will discuss potential moral and legal implications for the treatment of non-human animal persons in chapter four.

Now that I have discussed the concept of personhood and have specified that I am mostly concerned here with the metaphysical sense of the term (with the physical being assumed, the moral to be discussed, and the legal to apply indirectly), I wish to move on to set some parameters around how we should approach the classification process itself. 


\section{Classifying Persons}

Biological minds, as we currently understand them, appear to consist of a highlyinterconnected network. Based on the observation that many capacities are closely related or are dependant upon each other, it would be justified to assume that if we could confirm the presence of characteristics that can reliably be tested for and detected, we could infer the existence of other characteristics known to co-exist with those. In general, the more basic and simple the characteristic in question is, the easier it is to test for, and the more complex the characteristic in question is, the more likely it is that we will find disagreement about its existence, its nature, or the interpretation of the outward behaviour thought to be indicative of the inner state.

As will become evident in the next chapter when I discuss the nature of particular mental capacities, we are often led to a much more complicated story than is anticipated given a simple starting point, revealing a web of multiple interrelated traits. For example, in discussing the nature of self-awareness, I find there to be at least three different types of self-awareness, with more complex types of self-awareness necessitating the existence of more basic forms of selfawareness. What becomes clear is that in having at least some of the more basic characteristics, the being in question is likely to possess a few others to at least a minimal degree.

Conceptually, it makes sense that our mental capacities are not completely independent from each other. And indeed, the study of human and non-human animal behaviour suggests that certain capacities are inter-dependant, and that "higher" functions are possible only because of the existence of certain "lower" functions. For example, in order for a being to be socially aware, they must first be self-aware. These connections between abilities will be discussed further in chapters two and three. The fact that mental capacities can be related in these ways can help us practically when we find a case in which it is unclear whether or not the being in question 
possesses certain, more complex, characteristics. For if it can be demonstrated that the being possesses certain characteristics in a rudimentary form, we may be able to infer, with relative confidence, that the being may also have a few other characteristics that have been observed to coincide with the ones the being has demonstrated. Giving the being a sort of benefit-of-thedoubt is the more charitable approach and is consistent with the nature of evolutionary continuity as we understand it. This makes this charitable attribution a justified one and is not a blind leap. Especially in the case of non-human animals who cannot articulate to us the nature of their inner lives, we must make some educated guesses.

Making inferences in this way would be accurate for most cases when we are examining typically functioning adults. However, not all members of a species are typically functioning adults. Here I would like to briefly discuss two interesting features of the personhood debate: The fact that an individual's personhood is or can be transient, and that the cognitive abilities of some adult members of a species can be exceptional (significantly higher or lower than average). I will mention each of these issues in turn, although it is beyond the scope of this thesis to investigate them thoroughly.

A division is sometimes made in the category of persons between what are called "full persons," "partial persons," and "potential persons." A full person is a being who meets all criteria for personhood. A partial person is someone who may meet some of the criteria but not others. Alternatively, they may be individuals who have all the traits in question but have them to a lesser degree and whose abilities are just below the required threshold levels. A potential person is someone who presently does not meet all the criteria for personhood but is expected to meet the requirements as they develop and/or come into adulthood. In this sense, most, if not all full persons at one time were potential persons, assuming most animals (human and non-human) 
are not born with fully developed mental capacities. This fact opens up questions about whether a person needs to always meet all the criteria for personhood throughout their life. We could ask if an individual's personhood status should be removed if they lose their capacities, and wonder how to classify potential persons like fetuses or infants or partial persons. Such questions about identity and time are important metaphysical questions. However, investigating these issues are beyond the scope of this thesis and so will be bracketed. ${ }^{22}$

It will be assumed in this thesis that the species or individual beings referred to in my examples and analyses are fully developed adults and are representative of the average member of their species in terms of cognitive ability (unless specified otherwise). And I suggest that we assume that all members of a species are persons if their average member is. This suggestion is based on the fact that the vast majority of individual members are typical of their species in terms of cognitive abilities, and extending personhood status to all members would be appropriate for most cases. It would be too onerous and simply not necessary to examine every individual to prove that they are a person (which would be a never-ending task).

One strength of my conception is that it defines the minimally necessary criteria for personhood rather than suggests sufficient criteria. In doing so, I define the threshold for classification itself. Determining the personhood status for species about which we have sufficient data, will not be very difficult. But this still leaves open the question of how my conception of personhood (or any conception for that matter), would take up the task of

22 For literature that does discuss these issues see Robert Larmer's article, "Abortion, Personhood and the Potential for Consciousness," and James Digiovanna's article, "You Are and Are Not the Person I Once Knew: Eclecticism and Context in Continuity of Identity." 
determining the personhood status of lesser known species and how to deal with exceptional cases, should they come into question. In the case of unknown species, we would have to study many individuals in order to approximate what is typical for them. While this may take time, we can at least be assured that an answer will come in time. The issue of exceptional cases requires some harder thinking.

Individuals with a severe cognitive disability or those who are unusually intelligent are, by definition, not typical and not representative of their average species member. ${ }^{23}$ It is acceptable and still consistent with my conceptions of persons if there are many differences between individual persons within the same species. And individuals who are unusually intelligent would not present a problem, since their abilities would be of a higher degree than the representative member. However, those individuals who are severely cognitively disabled do present a challenge, since this kind of disability may result in the individual no longer possessing the characteristics relevant for personhood classification to the minimal degree.

In the human context, typically all fully functional human adults are considered persons without question. Although humans are usually automatically thought of as persons, the status of abnormally functioning humans is often questioned since the very capacities that tend to define a person are often absent or severely limited in these individuals. The types of individuals in this classification "grey-zone" include fetuses, the severely mentally disabled (either from birth or as a result of injury), and humans in a coma. Mary Anne Warren considers the personhood of fetuses in her article "On the Moral and Legal Status of Abortion," and Eva Feder Kittay

23 I am not concerned with physical disabilities since the requirements for personhood I set out all concern one's mental, rather than physical, abilities. 
considers the personhood of the severely cognitively disabled in her article "At the Margins of Moral Personhood.”

Warren claims that being human is not a criterion we should look to in determining whether a being has rights. Rather, we need to consider whether or not they are a person and thus are a member of the moral community. ${ }^{24}$ For Warren, the moral community consists only of persons, those who have full rights. She defines a person as a being who is conscious; can feel pain; can use reason to navigate novel and complex problems; can be self-motivated (as opposed to having actions determined solely by genetic and environmental factors); has communication abilities that allows for an indefinite amount of content; and has self-concepts and selfawareness. $^{25}$

For Warren, any being that does not satisfy any of these criteria is not a person fulfillment of every one of these criteria is necessary for personhood. Since fetuses do not possess all (or even many) of these criteria, she claims that fetuses are clearly not persons. As such, fetuses have no membership in the moral community and cannot and do not have rights (or at least they cannot be ascribed full rights). She goes further and claims that being person-like is also not sufficient grounds for ascribing rights and being classified a potential person is also insufficient since the very ideas of resemblance and potentiality suggest that not all criteria are fulfilled in the present.

Kittay likewise seeks to determine what constitutes membership in the moral community, but she comes at the issue from a very different perspective. Kittay's interest in the area of

24 Mary Anne Warren, "On the Moral and Legal Status of Abortion," The Monist 57, no. 4 (1973): 2.

25 Warren, "Status of Abortion," 5. 
personhood and moral status grew out of her experiences with her daughter, who was born with a severe cognitive impairment. Kittay calls into question capacities like rationality and full autonomy as requirements for personhood. She claims that theorists have not taken seriously other capacities that are also meaningful for membership in a moral community and that make someone deserving of equal respect. Because traditional accounts require "higher" functions as criteria for personhood, such as problem solving, rationality, and intelligence, individuals like Kittay's daughter constantly get excluded from being considered a person. ${ }^{26}$

Kittay's experience with her daughter and other severely disabled individuals has made her question what it means to be part of that moral community, believing that these individuals absolutely do matter morally and that they do contribute to the community, albeit in different ways. They contribute by having a sense of what is good, by appreciating the efforts of others, by caring, loving, and invoking a sense of care, empathy, and love in others. ${ }^{27}$ And certainly these individuals are moral recipients. Kittay admits that while it may be hard to determine the extent to which people like her daughter can have a sense of their future, can think rationally, or have rich internal experiences, it is clear that they can bring good into the world and have a sense of self. It seems to me that people like her daughter would also have emotions and interests, which would likely qualify her as a person on my account. Kittay believes these attributes, while perhaps minimal compared to the normally functioning human, matter.

26 The notion of a moral community is often presented as contractarian in nature. When morality is understood as an agreement between individuals for mutual benefit it makes sense that only rational, moral agents could be included in such a community. This is not the way in which I think moral communities should be defined, but it is beyond the scope of this thesis to discuss the notion of a moral community at length.

27 Eva Feder Kittay, “At the Margins of Moral Personhood,” Ethics 116 (2005): 122. 
I believe Kittay is on to something here. One thing Kittay and I have in common is the way we subvert traditional conceptions. She challenges the conventional understanding of what it means to be part of the moral community by pointing to an unjustified prejudice in the criteria required for personhood and by showing that there are other aspects of what it is to be part of a moral community that have been ignored. The move I wish to make in coming up with my own definition of personhood is very similar. I too find the traditional set of criteria required for personhood untenable and believe that "higher" functions such as problem solving, rationality, language, and the like, have unjustly been privileged.

I agree with Kittay that, in general, those qualities of an individual that are not hypercognitive, such as being a moral recipient, have not been taken seriously enough. As was mentioned in the introduction to this thesis, it seems that historically humans have tried to distance themselves from non-human animals, often by appeal to the "unique," hyper-cognitive abilities of humans as the important differentiating characteristic. Whether we look back at Plato, ancient myths, the teachings in the Bible, or the thoughts of famous philosophers like Immanuel Kant, we see a general trend of wanting to disassociate ourselves from non-human animals. We have become uncomfortable with parts of ourselves that are "beastly," primal, and instinctual.

Perhaps further fostering a negative view of "animal" characteristics has been the association of femininity and women with animality and animals. In both antiquity and early modernity, women were associated with and construed as overly-emotional, unintelligent, incapable, and submissive, contrasting with the image of men as logical, rational, highly 
intelligent, and dominant. ${ }^{28}$ This sexism and the preference for masculine, "higher" functions seems to have influenced our ideas about what counts or matters morally.

While these "higher" human functions may be relevant to other inquiries, such as deciding whether or not one has the right to vote, I don't think they are relevant to the question of whether or not a being can be directly harmed. ${ }^{29}$ By requiring hyper-cognitive abilities for personhood, the threshold is being set unfairly and unnecessarily high. The possession of other, more "basic" capacities - subjectivity, emotions, and interests - are all that are required for my account.

In the following chapter I will provide a fuller argument for why language and rationality - sophisticated and hyper-cognitive characteristics respectively - should not be required for personhood status. And following this discussion, in chapter three, I will argue for and defend my own conception of persons.

28 For more on this topic, see Adams, The Sexual Politics of Meat: A Feminist-Vegetarian Critical Theory.

29 Gary Francione similarly believes that requiring "higher" functions is not necessary for personhood or for membership in the moral community. He believes that only sentience is required. Cf. Francione, Animals as Persons: Essays on the Abolition of Animal Exploitation, 129-147. 


\section{Chapter 2}

Challenging the Moral Relevance of Language and Rationality

This chapter aims to challenge the moral relevance of language and rationality for personhood. While those who possess language and rationality will also be subjects with emotions and interests, language and rationality themselves are not useful as criteria for classifying persons. These characteristics represent a degree of sophistication and ability that is well above the minimum threshold requirements for personhood classification on my account. One can be a subject and have emotions and interests but not use language or possess rationality. The ability to communicate using language proper is only morally relevant to personhood if one believes rationality and language are inter-connected, and one requires rationality (or moral agency) for personhood.

The specific line of argumentation I will be objecting to in this chapter is what I will call "the exclusive position." A version of this view can be seen in the work of Aristotle and Kant. ${ }^{30}$ The exclusive position states that rationality and language are inter-connected such that the ability to use language proper gives rise to the type of thinking needed to be rational. Because one must be a moral agent (which requires rationality) in order to be an object of moral concern or to be a member in the moral community, ipso facto one must also have the ability to use language proper. I refer to this line of argumentation as the "exclusive" position since it excludes most beings from the realm of moral consideration and its membership base consists only of elite, or "higher" beings.

30 See Aristotle, Nicomachaean Ethics, and Kant, Critique of Pure Reason. 
To begin the discussion, I will focus on language, distinguishing between behaviours that are merely a reflection of internal states, behaviour that is communicative, and language proper. Here I will argue that communication using natural signs, such as facial expressions and body orientation, achieves the same basic goal as communication that takes the form of human language, or language proper. Here, I will claim that drawing a line between language proper and sophisticated forms of non-human animal communication is arbitrary and presents a challenge for the exclusive positon.

Section two of this chapter will make a similar move as section one. To begin, I will discuss the nature of rationality and give an example of reasoning in the non-human animal context. By understanding rationality as an ability that comes in degrees, in the way that language or communication comes in many legitimate forms, it becomes hard to deny that many non-human animals possess some degree of rational thought. We must then conclude that either some non-human animals do have linguistic abilities because they seem to act rationality, or we must conclude that the connection between language proper and rationality as proposed by the exclusive position is not completely accurate. Either way, a problem is presented for the exclusive position. In addition to this discussion, I will also draw an important distinction between being able to engage in rational moral deliberation, participate in a moral community, or possess moral agency on the one hand, and being an object of moral concern on the other. ${ }^{31}$ This

31 Despite Peter Singer being referred to as the father of the non-human animal rights movement, even he defines persons as having rational capacities. In another of his well-known books, Practical Ethics, Singer claims that a person is "the term for a being that is rational and self-conscious, aware of itself as one being among others, extended through time" (74-75). Thus, not only does my conception of personhood vary from his by taking a rights-based approach rather than a utilitarian one, we also have a different conception of personhood itself. 
distinction, which I take to be legitimate, is likewise problematic for the exclusive position since it conflates these two groups of beings. ${ }^{32}$

\section{Language}

To begin, I would like to distinguish between behaviours that are merely a reflection of internal states, behaviour that is communicative, and language proper. I will discuss each these in turn, providing examples. At its heart, communication in all its forms represents an extension to and a reaching towards others. Broadly construed, I define communication as a directed attempt to indicate something to others. By "indicate," I mean to impart, alert, bring attention to, or share with. I keep this broadly defined to capture the many reasons for wanting to communicate with another.

Many organisms move their bodies and change their vocal tones unconsciously in response to an inner experience. These types of behaviours are indicators of those experiences or states, but should not be confused with communication. For example, sometimes my cat companion, Sophia, makes vocalizations while sleeping. Perhaps she is reacting to a dream. When she does this, she is not trying to indicate something to me. While she is making vocalizations, which is one method of communication, there is no intention or directedness in this act.

32 Of course, the fact that most human persons are moral agents and many, or perhaps, most, non-human animal persons are not, is a morally relevant difference. Moral agents can be held to a different, higher standard of conduct compared to those who are only moral recipients. However, such a difference does not make one more or less morally important than the other on my account. 
In contrast, a communication attempt is a directed attempt to indicate something to others. As Bernard Rollin mentions, non-language users often use "natural signs" as means of communicating. Natural signs include glances, a touch, a look, an expression, a particular bodily orientation, vocalizations such as a whimper, and even silence. The communication style we observe and use with our non-human animal companions seems to consist mostly of natural signs, and a lot of important, deep communication between humans is also achieved using them.

When Sophia is hungry, goes to her empty food dish, and then finds me in another room and meows at me, this seems like an attempt to communicate. Even in those instances where I am unsure what she is meowing about, when she approaches me, looks at me, and meows, it is clear her vocalizations are intentional and directed..$^{33}$

Although this behaviour may seem simple, it has several layers of complexity. For instance, in order to direct one's attention towards others one must have some level of social and self-awareness. Communication as I define it also implies the ability to act with intention and suggests that the communicator may have desires they are seeking to have fulfilled. In this example, Sophia appears to be indicating a desire for food, and it seems reasonable to suggest that she is engaging in a basic form of problem solving. Namely, she is attempting to solve the problem of (a perceived) food shortage. ${ }^{34}$

33 Classifying an act as communicative needn't require that those attempts be accurately understood by the recipient of the communicative act. Although the ability to "converse" implies that the communicative behaviours were successful in sending the intended message, it is enough that a being attempts to communicate to imply that they have intentionally reached out to others. 34 For an article discussing the nature and contents of non-human animal communications, see Andrew McAninch, Grant Goodrich, and Colin Allen, "Animal Communication and Neoexpressivism." 
Here one might suggest that it is not problem solving that drives Sophia to seek me out, but simply that she has associated me with receiving food. I agree that it is likely that Sophia does have an association between me and food. But she seems to seek me out for reasons other than food as well, such as for affection. When she appears to want affection, her vocalizations and body movements differ from when she appears to want food. Consistently behaving differently towards me in these two scenarios shows an ability to discriminate between different associations with the same individual - an ability that seems to be more sophisticated than the mere ability to make associations. If all she had were indistinguishable associations between me and food, and me and play, and me and affection, then every time she saw me she would be confused as to which of these things she would receive from me. But her behaviour does not seem to indicate such confusion; her behaviour is unique in each of these circumstances. Given this, her meowing at me after finding an empty food bowl seems to be best explained as an act of communication.

Bernard Rollin claims that it is inconsistent to consider natural signs as legitimate indications of human needs and interests, yet deny their role and significance when non-human animals behave in these ways. ${ }^{35}$ He further claims that there is no legitimate line that can be drawn between communication in the form of natural signs vs communication in the form of language proper. Surely language proper represents a more sophisticated method of communication, but it is not fundamentally different. ${ }^{36}$

35 Bernard E Rollin, Animal Rights and Human Morality, 3rd ed. (New York: Prometheus Books, 2006), 98.

36 Ibid. 
Language proper is one style or method of communication, but it is not the only one. By language proper I refer to "human language" i.e. verbal or sign language. Both verbal and sign language consist of a large vocabulary of words, concepts, or referents, which follows a syntax, can be composed into unique sentences, and can be represented symbolically. ${ }^{37}$

The ability to use language proper is often believed to be an indicator of the presence of thoughts, the existence of a self, and self-awareness, among other capacities. ${ }^{38}$ Because of the cognitive sophistication that is required to use language proper, Chan and Harris believe that some non-human animals can be classified as persons based solely on their ability to learn sign language, use words, or communicate symbolically, such as chimpanzees, dolphins, and parrots.

The presence of language proper makes determining one's personhood status much easier since the being in question can communicate with us in a way we can understand well. Thus, we can easily confirm whether they have the characteristics required for personhood status. In addition, the ability to use language proper suggests a level of cognitive sophistication beyond the minimal requirements I have set out, and as such, language proper is not a useful classification criteria for my account. The only thing we should interpret from a species' or individual's inability to use language proper is that there is no direct, easy way of confirming the nature and sophistication of their mental life.

While the presence of language proper is sufficient evidence that the minimal complexity required to be considered a person exists, it is not strictly necessary for personhood. Chan and Harris do not require language proper for personhood status and do not believe that language

37 And, in the case of humans, the ability to represent ideas symbolically additionally allows us to communicate with and express ourselves in a unique way, such as when we journal or paint.

38 Chan and Harris, "Human Animals and Nonhuman Persons," 312. 
proper is required for the ability to think, use logic, or be self-aware. ${ }^{39}$ This is because many nonhuman animals have demonstrated in studies that they have these traits, yet do not use language proper.

But some non-human animals have demonstrated the ability to use language proper. A gorilla named Koko became famous for her ability to use American Sign Language. She used ASL in a way that demonstrated she was not just signing at random, and when asked questions (either verbally or with ASL) about things like her emotional state and whether she was hungry she usually responded appropriately. She could also sign novel sentences and indicated an understanding of the concept of "self." 40

While dolphins cannot use ASL, it has been found that they possess a complex communication system that is very similar to language proper and they can even communicate symbolically when given a chance. The Speak Dolphin Project, founded by researchers Donna and Jack Kassewitz, studies the harmonic vibrations dolphins use to communicate with each other as well as the role and meaning of play in dolphins. They have discovered that dolphins' vocalizations contain complex musical forms and a frequency range beyond the capacities of human hearing. ${ }^{41}$ The project has also hosted play sessions with the dolphins and crew where they play a game collaboratively. The game, observed as a natural behaviour of the dolphins, consists of swimming around with a string of seaweed (or ribbon), dropping it, and having another player pick it up and do the same - somewhat like a game of catch. Without any practice

39 Chan and Harris, "Human Animals and Nonhuman Persons," 312-313.

40 Francine Patterson and Wendy Gordon, "The Case for the Personhood of Gorillas," in The Great Ape Project, ed. Paola Cavelieri and Peter Singer (New York: St. Martin's, 1993): 58-77. 41 "Dolphin Language Analysis," Speak Dolphin, accessed February 19, 2017, http://www.speakdolphin.com/ResearchItems.cfm?ID=14 
or training, the dolphins and humans were able to play by a set of rules with each other. The project has also developed boards with pictures on them that are used to successfully communicate with the dolphins, showing that dolphins can communicate with symbols. ${ }^{42}$ All this evidence suggests that while dolphins cannot use sign language like apes, nor can they speak to us verbally in ways we understand (yet), they can certainly communicate (including symbolically) with humans in unambiguous ways.

As the case of dolphins hopefully illustrates, it seems arbitrary to draw the line at language proper for personhood status given the wide spectrum of communication styles. Requiring language proper as a criterion for personhood status seems to demonstrate a lack of appreciation for the variety of ways humans and non-human animals communicate. Signing or forming words the way we do requires a very specific physiology that many non-human animals do not have. If some non-human animals had advanced cognitive abilities but a physiology that did not allow them to communicate in either of these styles, then they would be wrongly disqualified from being considered a person.

The way in which exclusive accounts justify language proper as a requirement for personhood or as required to count as an object of moral concern is by claiming that the ability to use language proper is what makes rational thought possible. And since only moral agents (rational beings) are objects of moral concern, language proper is also a required ability. I will now discuss this purported relationship between language and rationality more specifically, as

42 Donna Kassewitz, "Games with Dolphins - a Key to Understanding Dolphin Language," accessed July 14, 2016, http://www.speakdolphin.com/ResearchItems.cfm?ID=12\#donna 
well as discuss the difference between being a moral agent (and being rational) and being an object of moral concern.

\section{Rationality}

Those that subscribe to the exclusive position believe that the ability to use language proper and the ability to be rational are intertwined. For them, the ability to use language proper entails the ability to have and use complex general and particular concepts. It is this ability to analyse particular cases in relation to general understandings that is the basis of the ability to reason. The ability to reason in this case refers to the ability to distinguish between and use general and particular concepts, to be able to understand past, present, and future, to be able to abstract, and to think in terms of possibilities. The exclusive position posits that the realm of moral concern consists only of those who are rational (such as moral agents). An implication of this view is that since non-human animals do not possess language proper, they cannot reason. And since non-human animals cannot reason, they are not objects of moral concern. ${ }^{43}$

This line of argumentation relies on the assumption that a stark and significant difference exists between language proper and communication as I defined it, that the reactions non-human animals have to stimuli are merely automatic and mechanical (as opposed to sometimes rational), and lastly, that those of moral concern are only those who are rational. These assumptions that underlie the exclusive position are ones I do not share (nor do all philosophers). The first assumption I have addressed in the previous section, although I admit it may be less clear

43 Rollin, Animal Rights and Human Morality, 62. 
whether non-linguistic communication involves the use of concepts in the aforementioned way compared to linguistic communication.

I will now address the claim that non-human animals cannot be rational. I would like to suggest that the ability to be rational, such as is exemplified in the ability to problem solve, can vary in degree. In the next chapter when I discuss what it means to have a concept of the self, I claim that the possession of a concept of $\mathrm{X}$ can come in varying degrees. Because objects and phenomenon can be complex and since no known animal species can immediately, upon first contact, become completely knowledgeable about a thing, it only makes sense to claim that the complexity of one's concept of $\mathrm{X}$ is dependant upon one's understanding of $\mathrm{X}$. But just because one may not fully understand $\mathrm{X}$, we should not go so far as to say that they possess no concept of $\mathrm{X}$ whatsoever.

For example, take a child in the eighth grade who is thinking about becoming a university professor as their career. Being around age fourteen, this child has some idea of what university life may be like, perhaps from hearing about it from an older sibling who is in university and seeing professors portrayed on television. However, we would not say that this child has a full and clear idea of what it is to be a professor. Their concept of professor and professorship is partially formed, and as they begin university themselves they will gain a better understanding of what it is to be a professor and as such their concept of professor and professorship will become fuller and more sophisticated.

Rollin discusses the ability to use reason in the same way. While most non-human animals cannot use language to tell us about or demonstrate their ability to reason, they have been observed to behave in ways that can only be called rational. For instance, the ability to solve a novel problem requires the possession of the (informal) concepts relevant to the situation 
and the ability to abstract from what is known to try something new (something possible). Rollin tells a story about the behaviour of a police dog that was told to him by the dog's trainer. This dog was trained to disable suspects by holding their arms, leaving them unharmed, until an officer arrived. If the suspect was very resistant, the dogs were trained to bite the arm they had a hold of. During the dog's first day on the job, two robbers fled the scene upon the arrival of the police, running down two different alleys. The dog disabled the first robber by biting his leg, then ran back to go up the second alley, disabling the second robber by holding his arm, keeping him unharmed. ${ }^{44}$

In this example, a dog, whose species is not thought to possess any proper language ability, demonstrated improvisation in the moment as part of complex problem solving. It is hard to classify this behaviour as a mere automatic, mechanical response to a stimulus. It is best explained as a rational act. ${ }^{45}$ As we see with humans, there is a range of ability to abstract, to think into the future, to plan contingencies, to problem solve, etc. The ability to reason seems to come in degrees. It is in no way a leap to attribute basic rationality to some non-human animals. This means that either such non-human animals actually do have some kind of linguistic ability, or that the connection between language and rationality proposed by the exclusive position is not completely accurate.

Another reason for doubting the exclusive position is its conflation of two categories of beings: those who are rational and are moral agents, and those who are objects of moral concern.

44 Ibid., 67.

45 Another commonly cited instance of rationality in non-human animals is tool use in crows. See Hunt, "Manufacture and use of hook-tools by New Caledonian crows." 
An advanced rational ability (such as that possessed by many humans) may legitimately be a factor of consideration if one believes that one must be able to mutually participate in a moral community. In chapter one I discussed Mary Anne Warren's definition of the moral community as one that consists only of persons, who, for her, are rational beings. Eva Feder Kittay criticized the idea that only those who can participate in certain ways can be part of a moral community. If we define the moral community, or the realm of those of moral concerns, as those who can fully understand all the rules of engagement, then it makes sense to require of its members an advanced rational and cognitive ability.

Like Kittay, Paola Cavalieri believes that the capacity to be rational is not required to be an object of moral concern. Cavalieri claims that traditional morality has divided the realm of humans from the realm of non-human animals on the grounds that humans can reason and nonhuman animals cannot. She summarizes the traditional line of thinking as follows: Since morality is only possible because of rational thought, only those who are rational (moral agents) are part of the realm of moral concern. Since most non-human animals cannot reason and/or are not moral agents, they are not of moral concern. ${ }^{46}$ The error in this line of thinking according to Cavalieri is the move from the premise that only moral agents can be morally responsible to the conclusion that only our actions towards rational beings have full weight. She claims that the conditions that make morality possible are distinct from morality's objects of concern. ${ }^{47}$ I will come back to these ideas in chapter four.

46 Paola Cavalieri, “Are Human Rights Human?," in The Animal Ethics Reader, 2nd ed.. Ed. Susan J Armstrong and Richard G. Botzler. 30-35 (New York: Routledge, 2008), 31-32.

47 Cavalieri, “Are Human Rights Human?,” 32. 
I agree with Kittay's and Cavalieri's positions, and it is my hope that the theory of personhood being defended in this thesis exemplifies a departure from these traditional assumptions. The realm of moral concern should consist of not only those who can understand and participate in its rules of engagement, but also all those who can be personally affected by those rules of engagement, and by the actions of moral agents generally. And as Rollin rightly points out that, if the realm of moral concern consists only of rational language users, then why do we resist traditional definitions of personhood that exclude humans who are not rational and cannot use language, like infants and the severely cognitively disabled? According to Rollin, the features we keep being drawn to in determining the rightness and wrongness of actions is not the action's effects on one's rationality or language, but rather, whether it prevents or causes suffering, and whether it generally effects well-being. ${ }^{48}$

An individual who possesses language and rationality as traditionally defined would seem to require some degree of metacognition to make this possible. Metacognition is usually understood to be a type of thought that takes as its content one's own mental states or desires. It is the ability to think reflectively about oneself and one's own thoughts, feelings, or desires. I do not think metacognition is required for my account of personhood, for to be a subject and to have emotions and interests does not necessitate having such reflective capacities. More will be said about metacognition and other types of self-awareness in the next chapter.

In conclusion, the ability to use language proper and be rational is not required for a being to be a subject and have emotions and interests (as I define these notions). Historically, it seems we have looked for language proper and rationality as (sufficient) indications of

48 Rollin, Animal Rights and Human Morality, 73-74 
personhood. And while we may need rational capacities to deliberate about personhood and to determine which beings are persons and which are not, rationality (and language) themselves are not essential to being the kind of being who can be personally harmed. As Jeremy Bentham so famously said, it is not whether a being can reason, but rather if they can suffer that makes them matter morally. Since language proper and rationality do not constitute the threshold that separates persons from non-persons, they are not useful in my account. My conception of personhood, which will be presented next, requires fewer and less onerous characteristics for classification as a person. It is these characteristics that we should be using to identify persons. 


\section{Chapter 3}

\section{The Characteristics of Persons}

The aim of this chapter is to articulate and defend my own conception of personhood. ${ }^{49}$ Persons are those beings who can be personally or directly harmed. Thus, persons are subjects who have emotions and interests. Such beings are able to experience negative and positive states, such as suffering and contentment. As such, we have certain negative and positive obligations towards them, aimed at protecting them from harm and providing them with conditions conducive to their flourishing and success when possible. ${ }^{50}$

To be a subject, one must have an inner mental life to some degree and be able to recognize oneself as a distinct entity that is connected to one's experiences. To have subjective experiences one must be conscious, self-aware, and have some degree of psychological unity (to have a connection between mental states that allows for a continuous experience). To be capable of emotions (such as anxiety, fear, and contentment) is to have a perspective on one's experiences and is what makes an experience positive or negative rather than one of indifference. To have interests (such as the interest in finding food and staying alive) is essential for determining which actions harm persons and which do not, since the frustration of interests can have negative effects on one's health, cause suffering, and be undignifying.

49 For an informative article presenting a position similar to mine, along with criticisms of many other types of approaches to personhood theory, see Tooley, "Are Nonhuman Animals Persons?"

50 In chapter four I will discuss what may constitute harming persons, and give some preliminary suggestions about which negative and positive obligations we may have towards persons. 


\section{Subjectivity}

Persons are beings who can be harmed directly rather than indirectly - they themselves experience the harm done to them. Thus, persons are moral recipients in that they are the kinds of beings who can be wronged by moral agents. On my account, persons needn't be moral agents themselves. This is because the kind of harm that can be inflicted upon moral recipients, and the way in which moral recipients can experience harm, is morally significant. Although moral agents, or other beings with advanced cognitive abilities, may be able to experience more kinds of harm than moral recipients and less cognitively advanced beings, this fact is irrelevant to the question of whether or not moral recipients are capable of being harmed in a morally significant way.

Christopher Morris's discussion on the nature of moral status is helpful by highlighting what makes a being such a recipient, akin to those I call subjects. Morris claims that all things can be assigned a moral status, whether very significant or very insignificant. However, only certain things have a special (high) status he calls "moral standing." He defines a being as one with moral standing "if it is owed any moral consideration or duty whatsoever." ${ }^{51}$ Here he distinguishes between things like works of art on the one hand, and beings with moral standing on the other. A crucial difference between these two groups is that only beings with moral standing are the kind of beings or things that can themselves be harmed or affected by our

51 Christopher Morris, "The Idea of Moral Standing," in The Oxford Handbook of Animal Ethics, ed. Tom L. Beauchamp and R. G. Frey, 255-275, (New York: Oxford University Press, 2011), 264. 
actions. ${ }^{52}$ Even though we may save a work of art from destruction simply so that it continues to exist, the work of art itself does not care about its existence. But beings with moral standing do. ${ }^{53}$

Most of us automatically or intuitively know to which beings this notion of moral standing applies. Should you come across a dog who appears to be abandoned and alone in the cold, and should you decide to give her some of your food and perhaps even take her in for temporary shelter, you do so for the sake of the dog herself because these things are good for her. Your motivation for helping her is not simply the thought that it is good for dogs to exist in general or because you want to preserve someone's lost property in case they seek to reclaim it. 54

The fact that we have these experiences where we feel drawn to help non-human animals shows that we have some degree of personal connection to them - a connection based on both a sympathetic and empathetic understanding of their lives and their circumstances. On an intuitive level, we have an affinity with the dog and we can envisage ourselves, in a fleeting moment,

52 For a similar account that discusses different moral statuses and reasons to act, see Kamm, "Moral Status."

53 Morris, "The Idea of Moral Standing," 259-260.

54 It is useful here to mention the difference between direct and indirect duties - a distinction that commonly comes up in literature discussing the extent to which we owe things to nonhuman animals. Duties regarding a being are duties carried out not through a direct obligation, but an indirect obligation. They are duties that involve the being or thing in question, but are not duties that come about because of that being or thing. For example, we usually do not believe we have direct duties to plants, but when we agree to water our friend's plants for her while she is on vacation, we have a duty to uphold that promise. But that duty is to our friend, not the plants. Our duty is about the plants - it regards the plants - but it is not a duty owed to the plants themselves. In contrast, duties to a being are like those to our friend in this example. Our friend is a being with moral standing and when we enter into an agreement with her we have a direct duty to uphold it. Not doing so would constitute harm to her, not her plants. (Although I admit I do not know what the moral status of plants may be). 
becoming cold, hungry, and scared, just as we perceive the dog to be. What allows for this sympathetic and empathetic experience is the fact that we are connecting to another being who is also a subject. Humans and dogs (and many non-human animals) experience things in a way that plants and inanimate objects cannot. We are not by-standers to our existence; we are such that being able to experience our existence and ourselves is part of what makes us who and what we are. This is partly what makes a subject "personal" and individual.

Some use the label "sentient" to describe this characteristic. To be sentient is to feel pleasure and pain and perceive in a rudimentary way. Although sentience is a very commonly used and very useful term in the animal ethics literature, I do not believe it is the most precise way to describe what is special about persons. To be sentient as I understand it requires consciousness and an awareness of one's own body. But the notion of sentience doesn't seem to be inherently personal and doesn't clearly imply such a personal or individual nature. As such, it doesn't quite capture the "someone" versus "something" distinction I am trying to bring forth as the fundamental building block of personhood. Sentience also doesn't necessarily imply the existence of emotions and likewise doesn't clearly imply that such beings would have interests. While my definition of subjectivity may also not clearly imply the existence of emotions and interests, I believe it better describes the foundation from which emotions and interests are made possible. Therefore, while the meaning of sentience will be encompassed in my account, I prefer to use the term "subject."

Subjectivity is not singular in that it is a term that captures multiple aspects of mental life. Although some equate subjectivity to sentience, self-consciousness or self-awareness, these notions are conceptually distinct, and equating them with subjectivity or being a subject fails to account for its complexity. When we carefully unpack the notion of subjective experience and 
incorporate a phenomenological understanding, we find that subjective experience is multidimensional, consisting of many separate components that work together to make subjectivity possible.

What it means to have subjective experience (and thus be a subject) is to have a phenomenological world that is accessible by only one individual - the self. It is the experience of experiencing something as a subject - to have one's pains, pleasures, moods, thoughts, and desires centre around and connect to a single, internal location. As such, subjects are the kinds of beings who can be harmed and can experience the harm done to them. They are the kinds of beings to whom it matters whether or not their needs are being met. ${ }^{55}$

The capacity for subjective experience is a fabric, consisting of multiple inter-related traits and cannot be reduced to any single one of them. ${ }^{56}$ The capacity for subjective experience requires consciousness, some degree of psychological unity, and self-awareness. Sometimes it is thought that to truly be a subject, one must possess a concept of "I" and be able to identify oneself as such. While I believe it is true that many subjects understand themselves abstractly in

55 How we can know the subjective experiences of others is a topic of philosophical debate. On the extreme end of this spectrum is the idea that not only can we not know the experiences of others, but we cannot escape our own minds enough to even know about the world. While I agree that it is difficult to know the contents of another's experience, we are not so solipsistic that we cannot identify the existence of a subjective life in another. Knowing the exact contents of another's mind is not necessary to determine their personhood status. But identifying the existence of an inner mental life using their behavioural cues as indicators of general internal states is a valid way to determine the general complexity of a being, and thus whether they are a person.

56 Understanding subjectivity as consisting of multiple dimensions rather than as a singular characteristic also fits better with our current understanding of the brain, evolution and the similarities between species. On one understanding of evolution, it is continuous and occurs as parallel across species. On that account, mental capacities differ in degree and not in kind, and it explains how different species share basic mental capacities but then diverge and differ from one another in the complexity and nature of those capacities. 
this sense, I do not think this level of understanding is required for an individual to have subjective experiences. I will now discuss these components of subjectivity in turn.

\section{Consciousness}

The nature of consciousness is a topic of continual debate in the philosophical and psychological literature. But what has become generally accepted is that the kind of non-human animals I am concerned with on my account possess it. Authors Sarah Chan and John Harris describe consciousness as a kind of basic awareness, but they do not attempt to give a full definition of it given that there is no generally accepted definition in philosophy. They claim that we can safely assume that most non-human animals are conscious, basing their claim on the fact that there is a high degree of continuity in the evolution of behaviour and anatomy. Given that we believe humans are conscious, and since humans serve as adequate analogues for nonhuman animals, we should grant that non-human animals are conscious as well. ${ }^{57}$

Using a similar line of reasoning, Bernard Rollin claims that, based on evolutionary continuity, the presence of the following physiological markers in a non-human animal indicates the existence of consciousness and a mental life: a nervous system, chemical compounds that affect mental states in humans, behavioural reactions to pleasant and unpleasant stimuli, and the presence of sense organs (eyes, ears, tongue, etc.). ${ }^{58}$ To claim that any non-human animal that possesses any of these characteristics is not conscious would not be coherent.

57 Chan and Harris, "Human Animals and Nonhuman Persons," 314.

58 Rollin, Animal Rights and Human Morality, 102. 
While it is beyond the scope of this thesis to try to come up with a detailed theory of consciousness, it is necessary to discuss it to some extent. One understanding of consciousness is from Gary Francione. Drawing on the work of neurologist Antonio Damasio and biologist Donald Griffin, Francione distinguishes between two different degrees of consciousness: "Core consciousness" and "extended consciousness." ${ }^{.59}$ Core consciousness is what provides awareness of the present moment and of the present self. Possessing core consciousness entails that there is a consciousness of the self, which means that being able to perceive the movement of one's body is to perceive that it is oneself that is moving. To have even this basic form of consciousness of the self and the world also implies a continuous mental existence, however simple it may be. ${ }^{60}$

In contrast, extended consciousness is connected not just to the present, but to the past and future as well. It allows us to reason, it is integrated with our memory, and it is what allows for an autobiographical sense of self through time. Language ability is not a main component of extended consciousness but is an indication of the highest form of extended consciousness. ${ }^{61}$ Extended consciousness comes in degrees, with human consciousness being its highest known form.

As something that can manifest to different degrees, different species may have varying levels of depth in their autobiographical understandings of the self, varying senses of time, and varying reasoning abilities. According to Damasio, some non-human animals such as chimps,

59 See Griffin, Animal Minds: Beyond Cognition to Consciousness, and Damasio, The Feeling of What Happens: Body and Emotion in the Making of Consciousness.

60 Francione, Animals as Persons, 55-56.

61 Ibid., 56-57. 
dogs, bonobos, and baboons seem to have an autobiographical sense of self, indicating they have a moderate to high degree of extended consciousness. ${ }^{62}$

I understand consciousness to refer to one's phenomenal field - the mental, perceptual space wherein experiences take place. To be merely conscious is to possess the most rudimentary phenomenal field. Possessing higher degrees of consciousness, therefore, means having a larger, more layered phenomenal field, and such a field means one may be capable of a wider range of experiences. The notion of core and extended consciousness articulated above capture this experiential aspect of being conscious. However, these notions do not capture the physiological aspect of consciousness - that which makes experience possible and explains why some creatures seem to have varying degrees of complexity, and seem to have varying depths to their experiences in the first place. I believe this physiological, structural aspect of consciousness is captured by the notion of "psychological unity."

Chan and Harris take up Jeffrey McMahan's conception of psychological unity, defining it as the level of connectedness between mental states, the richness of those states, the coherence and complexity of one's "psychological architecture," and the continuity of experiences. ${ }^{63}$ The degree of psychological unity a particular being has seems to be mostly a function of their anatomy and individual intelligence. Brain functions are dependant mostly on the form and structure of the brain, which in turn is dependant upon one's species and individual genetics. However, environmental factors, such as amount of stimulation and education, can also influence the range of one's abilities. Thus, the degree of psychological unity any one being has will be

62 Damasio, The Feeling of What Happens, 198 - 201.

63 For more on this notion, see McMahan, The Ethics of Killing. 
similar between species (consisting of a general range as per their species norm), but can also vary from individual to individual. ${ }^{64}$

The concept of psychological unity describes the physiological, material basis of consciousness whereas the notions of core and extended consciousness describe the phenomenal, experiential aspects of consciousness. Together, these notions work well to cover these two main features of consciousness. ${ }^{65}$ Since most non-human animals cannot communicate complex information to us, we cannot gain "direct" access to the contents of their mental life. But by getting an idea of the degree of psychological unity a being has we can approximate what kinds of experiences they may be capable of. I will now discuss how we may do this.

Chan and Harris' account of personhood centres around the claim that a being must be capable of valuing their existence. This entails not only valuing one's present existence, but one's future existence as well. According to them, this ability requires that the being can make connections between different points in time and conceive of themselves as existing through time. ${ }^{66}$ In order to do this, a being must have a moderate level of psychological unity. Such a being has some depth to their experiences and mental states, and experiences their environment and inner life as connected and inter-related. Chan and Harris claim that one indicator of psychological unity, or mental continuity between past and present, is the ability to form

64 For psychological literature discussing the influence of genetics versus environment on intellectual abilities, see Dickens and Flynn, "Heritability Estimates Versus Large Environmental Effects: The IQ Paradox Resolved."

65 For psychological literature that suggests that consciousness has both a material, or physiological aspect and an experiential aspect, see Davidson, "The Physiology of Meditation and Mystical States of Consciousness," and Düzel, Yonelinas, Mangun, Heinze, and Tulving, "Event-related Potential Correlates of Two States of Conscious Awareness in Memory." 66 Chan and Harris, "Human Animals and Nonhuman Persons," 316. 
memories, and one way to demonstrate the ability to form memories is to demonstrate the ability to learn.

Evidence that many non-human animals are capable of learning is now widely accepted. The most basic and primitive kind of learning is known as "associative learning" - the ability to remember or learn that event $\mathrm{A}$ is associated with event $\mathrm{B}$. This type of learning is the underlying mechanism of classical conditioning - the reason why Pavlov's dog salivates to the sound of a bell in the absence of food. Associative learning can - but does not always - take place almost entirely unconsciously, thus the degree of psychological unity required for this ability would be on the lower end of the spectrum.

Many non-human animals have demonstrated more sophisticated learning techniques, such as social learning. Social learning has been observed in fruit flies, chimps, cats, cetaceans, and more. Social learning occurs when an individual observes the behaviour of another and then models that behaviour themselves, or uses the behaviour of others to know which behaviours to avoid. Examples of behaviours that are learned socially, at least in part, include: choosing a mating partner, courtship practices, which foods to eat, where to nest and lay eggs, migration routes, predator and prey recognition, and how to use tools. ${ }^{67}$ The capacity for social learning implies a much higher level of cognitive complexity than mere associative learning and seems to require bodily and social self-awareness, an understanding of consequences, the ability to act intentionally, memories, and the ability to go beyond mere biological programming and try something novel.

67 Bennett G. Galef, "Social Learning and Traditions in Animals: Evidence, Definitions, and Relationship to Human Culture," Wiley Interdisciplinary Reviews: Cognitive Science 3, no. 6 (2012): 581. 
Chan and Harris propose an additional indication of (a high degree of) psychological unity: the possession of episodic memory. They claim that episodic memory requires a strong sense of self, an understanding of one's existence through time, and a high degree of psychological unity. ${ }^{68}$ Episodic memory refers to the ability to "re-live" past experiences to some degree. It is like a sort of "time travel" where you can recall an experience you had with moderate detail. Sometimes the recall can feel like watching a film of your past. Episodic memory is also in play when imagining and contemplating the future. ${ }^{69}$ Possessing the ability to recall the past or project yourself into the future in this way certainly implies that there is an enduring sense of self from past to present, and through to the future.

Proving that a particular being has episodic memory is very difficult since it is an "action" that takes place entirely within the confines of the mind. Despite this, there is some evidence from studies that a few non-human animals likely possess it. Testing for the possession of episodic memory can only be performed on those non-human animals who have sophisticated language abilities, such as great apes and cetaceans, since only these beings can convey information to us in an understandable way. ${ }^{70}$

In sum, one way to approximate the degree of psychological unity a being has, and thus approximate the depth and complexity of their phenomenal experience, is to assess their learning capacities and whether they seem to possess episodic memory. An indication that a being may not be capable of learning at all may be that the being constantly makes the same mistakes and does not adjust their behaviour over time. However, it seems very few non-human animals of the

68 Chan and Harris, "Human Animals and Nonhuman Persons," 316.

69 Ibid., 316-317.

70 Ibid., 317-318. 
species I am concerned with have no learning ability. If a being can learn by association or by observing others, we know that they have a low/moderate or moderate/high degree of psychological unity, respectively. The possession of episodic memory indicates a high degree of psychological unity.

Extrapolating from this information, we can approximate the kind of depth a being has in their experiences, how complex their world is, and, most importantly, the extent to which they may be the kind of being who can be harmed directly. While this information is useful, I have not yet described what makes conscious experience unique to an individual. Next, I will discuss a specific feature of consciousness for those who are subjects: self awareness.

\section{Self-awareness}

In contrast to phenomenal consciousness, which refers to one's phenomenal field in general, the notions of self-consciousness and self-awareness refer to one's experience of the self specifically. To be self-conscious or self-aware is to have an experience of the self within one's

phenomenal space, however distant, indirect, or rudimentary this experience of the self may be. Self-awareness and self-consciousness both refer to one's understanding and conception of the self within one's own conscious experience.

It seems that this self-understanding can be either referential or abstract. In this section, I will first discuss self-awareness, which, in its more basic forms, is referential in nature. By a referential understanding of the self I mean an understanding of the self in and by reference to itself (directly) or in reference to others or one's environment (indirectly). Second, I will discuss self-consciousness, which I take to be abstract in nature. By an abstract understanding of the self 
I mean being able to take the self as an independent object of consciousness that can be examined in isolation from outside referents. I will begin now with self-awareness.

In order to experience things as connected to the self, a being must be aware of themselves as a separate thing from others and their environment. Rather than be an indifferent observer of the world, a being must have a sense of themselves as a participant in the goings-on of their environment and understand that they can move about in the world. David DeGrazia discusses the nature of self-awareness and the extent to which non-human animals possess it in his article, "Self-awareness in Animals." Here he distinguishes between three types of selfawareness: bodily, social, and introspective self-awareness. DeGrazia's notion of "bodily selfawareness" describes this kind of awareness aptly.

Bodily self-awareness is awareness that “one's own body [is] importantly different from the rest of the environment - as directly connected with certain feelings and subject to one's direct control." $" 71$ To have this kind of awareness is to have proprioception - a sense of your body parts and their relative positioning and movement. It also entails having sensations that tell you both about the outside world as well as about your internal state, such as sensations of hunger, temperature, pain, itching, and pressure. Thus, bodily self-awareness is two-fold, including an awareness of body in this basic sense, and an awareness of being able to move and act in response to these sensations. According to DeGrazia, this is the most basic form of selfawareness, making possible higher forms of self-awareness, and he believes that most if not all non-human animals that are sentient possess it.

71 David DeGrazia, "Self-awareness in Animals," in The Philosophy of Animal Minds, ed. Robert W. Lurz (New York: Cambridge University Press, 2009), 201. 
The second type of self-awareness DeGrazia describes is social self-awareness, which he defines as "awareness of oneself as part of a social unit with differing expectations attaching to different positions." ${ }^{, 72}$ In describing what social self-awareness allows one to do, DeGrazia refers mostly to interactions within a group of one's own species. He gives the example of wolves, who are known to live in socially sophisticated groups. Individual wolves within a pack seem to be aware of who is dominant, who is subordinate, and which individuals will protect certain others if challenged. ${ }^{73}$ Non-human animal species who have complex social relations and form social groups provide the most obvious example of what it means to have social self-awareness.

Taking a broader look at social self-awareness, I would like to add that those individuals who do not live in social groups, or perhaps only live socially when they care for young, also likely possess a kind of social self-awareness. Not only is social self awareness a necessary trait if one is to live harmoniously in a social group, but it is also necessary to effectively interact with other creatures of different species. Almost no species lives their life without interacting with other species in some way. And in order to survive these encounters, a being must be able to understand others in at least a basic way. The capacity for social learning as described previously would serve as sufficient evidence for social self-awareness.

There is a sort of universal language between most animals that consists of shared natural signs that help us survive and interact successfully with other species. ${ }^{74}$ For example, certain body movements and positions are understood across most animal species as either threatening

72 DeGrazia, "Self-awareness in Animals," 202.

73 Ibid.

74 I use the term "animals" here instead of the usual "non-human animals" intentionally to include humans in this category, since we are known to behave these ways as well. 
or as submissive. This tells you whether or not to expect a fight or whether you can proceed without danger. Common behaviours seen in many species that indicate you are being threatened include loud, long vocalizations, fur standing on end, hissing, direct eye contact, lunges towards you, and moving the body to appear larger. Other behaviours that are social, but do not include direct interaction, include urinating to mark territory and leaving pheromones for mates. Whether innate, learned, or a combination of both, it is clear that such animals possess tools for social communication across language, cultural, and species barriers. And in this sense, these individuals would too seem to possess social self-awareness.

The third and last type of self-awareness DeGrazia describes is "introspective awareness," which he defines as "awareness of (some of) one's own mental states such as

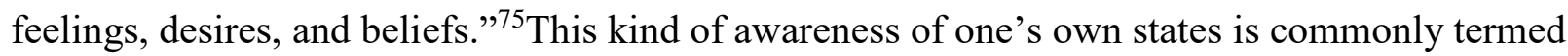
"meta-cognition." It is commonly held that meta-cognition is the highest level of self-awareness one can have, and it is believed that only humans, some great apes, and likely cetaceans have this ability. ${ }^{76}$

Introspective awareness or meta-cognition is not required for personhood on my account, but beings with meta-cognition will have the characteristics required on my account. Some accounts of personhood do require meta-cognition, such as the exclusive position discussed in chapter two. And in general, it seems meta-cognition is made into a requirement for personhood if moral agency is also required. To understand consequences, one's actions, and rightness and wrongness, it makes sense to think that the being must be able to think about their own mental

75 DeGrazia, "Self-awareness in Animals, 202.

76 Chan and Harris, "Human Animals and Nonhuman Persons," 318 
and physical states and about the minds of others. For reasons already given, I do not think persons need to be moral agents. In other cases, meta-cognition appears to be a required capacity because it seems necessary to have a concept of "I" or "self." For reasons that will be developed in the following section, I do not think that abstract understandings of the self, the kind that would require a degree of metacognition, are required for personhood and thus introspective awareness is not a crucial classification criterion.

To defend his thesis that many non-human animals are in fact self-aware in at least one of these three ways, DeGrazia claims that studies have found expressions of non-human animal behaviour that seem to require or indicate some level of self-awareness. A variety of well conducted studies have found that some non-human animals have desires; can act intentionally; experience fear; have anticipation of their own future; have memory of their own past; have the ability to imitate; can recognize themselves in mirrors; can take into account another's spatial perspective; use deception; possess a complex social understanding; and even seem to possess meta-cognition. ${ }^{77}$ The presence of these traits and behaviours indicate the presence of at least one of the three senses of self-awareness.

Determining the extent to which a non-human animal is self-aware by analysing their behaviours, as DeGrazia has done, seems like a reliable and justifiable way to approximate the degree of self-awareness they may have. But one indication listed by DeGrazia, the ability to recognize oneself in a mirror, known as the "mirror self-recognition test," is worth more discussion. This test for self-awareness is commonly employed and is also used to determine at what age human infants become aware of themselves. I find tests like this one problematic for

77 DeGrazia, "Self-awareness in Animals," 202-217. 
use as an indication of personhood for a couple of reasons. I will now describe this test and mention two reasons to doubt it as an appropriate test to use to classify non-human animal persons.

Chan and Harris believe self-awareness is required for personhood, and they too claim that the ability to pass the mirror self-recognition test is one way we can determine if a being is self-aware and thus may be a person. This test consists of placing a marker on the subject without their knowing and where they cannot see it without using a mirror, such as a dab of paint on the forehead. When placed in front of a mirror, if the subject seems interested in the mark on their actual body and begins reaching for it, this is supposed to indicate that they are aware of their physical body generally and that the reflection is of their body as opposed to that of another's. Human children usually demonstrate this around age 2, and various great apes, dolphins, and elephants have also passed the test. ${ }^{78}$

There are two issues I have with this test and tests of cognitive functioning like it. The first is that not being able to pass the test may simply be a function of not understanding what a mirror, a man-made object, is. Most non-human animals in the wild have never seen a mirror before and may not have been able to view too many clear undistorted reflections of themselves in the surfaces of water. Perhaps given several opportunities, a non-human animal could come to recognize that it is themselves in the mirror. Thus, not passing the test may be an issue of familiarity and experience, but this is difficult to determine.

Second, passing this test may indicate a level of self-awareness that is non-basic. That is to say that it is possible that only those beings with a more sophisticated awareness of self could

78 Chan and Harris, "Human Animals and Nonhuman Persons," 313-314. 
pass it. Since I require only a basic sense of self-awareness for personhood status, then this commonly cited test is not useful for determining eligibility. Using field observations rather than lab settings (labs being the places where mirror self-recognition tests are often done) to study self-awareness has the advantage of being able to observe non-human animals in non-simulated, familiar environments in which their repertoire of behaviour is unlikely to be limited or affected by a research environment. ${ }^{79}$ Regardless of the outcome of mirror self-recognition tests, scientific evidence and personal experience tell us that many non-human animals possess bodily self-awareness, and many also possess social self-awareness.

Passing the mirror self-recognition test indicates self-awareness in a way that is particularly recognizable to humans, but there are other ways to be self-aware that are less “cognitive." In general, analyses of mental states and psychological characteristics tend toward a cognitive understanding of the phenomenon. Humans privilege such a perspective often at the cost of minimizing the power and legitimacy of other (non-cognitive) perspectives. For example, across all mammal species, humans have a lower than average sense of sight, hearing, taste, and smell. These senses do not contribute nearly as much to an evaluation of our environment as they do for other species. Humans cannot hear the presence of others from far away, we cannot smell a tree and know how long ago another animal had passed by, and we cannot see very well in low light conditions, but many non-human animals can and do. In this way, many non-human

79 It is also possible that some non-human animals do not pass tests of cognitive ability in lab settings simply because of poor test design, their mood at the time, or their general temperament. I also acknowledge that some information can be acquired in a lab setting that may not be possible in natural settings, such as testing the limits of a non-human animal's problem solving skills by presenting them with more complex problems than they may encounter in the wild. However, the kinds of characteristics I am concerned with on my account can be observed in a natural setting. 
animals have a deeper and more precise sense and understanding of themselves, others, and their environment than humans do. It seems arbitrary to privilege a sense of self-awareness that is cognitive over self-awareness that comes from other senses. It is important to keep these kinds of considerations in mind as we move forward.

A subject is a being who can be personally affected by others and their environment. In order for this to be possible, one must be aware of themselves as a distinct entity and be the centre around which their experiences take place. As such, a being must possess DeGrazia's notion of bodily self-awareness. It may be argued that some sense of social self-awareness may also be required for my account of personhood, considering that, in having and seeking out one's interests, there must be an ability or mechanism that allows oneself to safely navigate an environment. A sophisticated type of social self-awareness like that seen in wolf packs is not required, but an awareness of others generally is required and is indicated by those basic universal signals, such as shared natural signs, which are understood across species.

\section{Self-consciousness and "I" Concepts}

The notion of self-awareness just described is relational in nature. To be self-aware is to distinguish oneself from the environment and from others and to be aware of what is going on in one's own body. In contrast, the notion of self-consciousness is abstract and includes not only an awareness of the self as different from everything else, but also typically describes the ability to think about the self in isolation from other referents. It is the ability to take the self as an independent object of consciousness that can be examined. Thus, to be self-conscious in this sense is to possess an abstract concept of "I." 
Chan and Harris liken self-consciousness to self-awareness, but their distinction between these two concepts is unclear. What is clear on their account is that being conscious is distinct from being self-conscious. According to them, to be self-conscious implies that there is an awareness of the self in a rudimentary way. By this they mean that a basic knowledge or sense of self, rather than a formal or abstract thought involving oneself as the subject is what constitutes a basic self-consciousness. They claim that having a concept of "I" or having thoughts involving "I" as a subject is not required for personhood nor is it even required for a being to act intentionally. They claim that a creature can act with intention, based on a desire, without formulating the thought that it is they who will act to obtain object $Y{ }^{80}$ Here it appears that what Chan and Harris are calling self-consciousness is what I have just described as self-awareness.

What I believe they are getting at in making this observation is that formal concepts about the self are not required for the possession of other characteristics sometimes thought to be those of persons, such as intentional action and desires. Gary Francione likewise believes that being able to think or iterate that it is "I" who am doing action $\mathrm{X}$ is not necessary for a real sense of self-awareness or self-consciousness ${ }^{81}$ I agree with these claims that consciousness is distinct from self-consciousness and that possessing a concept of "I" is not necessary to be a subject or be worthy of moral concern. However, more discussion is needed to investigate the difference between having a sense of self versus having a concept of "I" or "me," and how these notions fit into the broader notion of subjectivity.

80 Chan and Harris, "Human Animals and Nonhuman Persons," 315.

81 Francione, Animals as Persons, 56. 
Rocco Gennaro distinguishes between four ways, or degrees, of understanding the self in his article "Animals, Consciousness, and I-thoughts." He claims that there are degrees of understanding oneself as "self" or "I," from a brute sense of one's location to understanding that others too have minds. Most basic is the understanding of self as here rather than there, as this thing and not other things. The next degree of understanding is of the self as the source of one's mental life, as an experiencer of mental phenomenon. Third is the understanding of the self as a thinking thing existing through time. The forth and most sophisticated degree of understanding is of the self as one among many other thinking beings. ${ }^{82}$ Gennaro believes that most non-human animals possess at least the third level of self-understanding (they understand themselves as thinking things that exist through time).

It seems that the first and second degrees of self-understanding are similar to selfawareness as I have described it, and can be achieved through a referential understanding alone. The third and forth degrees of self-understanding begin to be more abstract in nature. Here we must now investigate what it might be like to have an abstract understanding of the self, and what it might mean to possess a concept of "I."

To determine whether or not one possesses a concept of "I," we must first look at what a concept, in general, is. One possible definition of a concept is that it is an abstract, consciously knowable understanding of a thing. This kind of concept is sophisticated, full, and can be applied to new situations to determine if new things are like or unlike other things. Doing this requires that one can examine things and can think somewhat critically. If this is what it is to possess a

82 Rocco. J. Gennaro, "Brute Experience and the Higher-Order Thought Theory of Consciousness," Philosophical Papers 22 (1993): 51-69. 
concept of something, then perhaps only beings with the third or fourth level of sophistication as per Gennaro's distinctions could be said to have concepts of things or be able to formulate a notion of "I" in the form of a thought. If having a concept of the self in this sense is required for personhood status, then it may be the case that many non-human animals would not qualify as persons.

Another possible definition of a concept, one that is less sophisticated, is that it is a whole or partial understanding of a thing, known through images, a sense, an unconscious or instinctual knowledge, or a basic understanding rooted in learning and memory rather than developed through abstraction. If a concept is understood as something more along these lines, then possessing a concept of the self may or not come in the form of a thought or an abstract notion. A concept of "I" could almost equate to DeGrazia's notion of bodily self-awareness.

At the very least, possessing a concept of $\mathrm{X}$ implies that one has some kind of understanding of $\mathrm{X}$ or that they can make sense of $\mathrm{X}$ in some way. Understanding comes in degrees, as is illustrated by human children through the early learning stages. Early in life a child may only have a slight understanding of $X$, but years later they may fully understand X. It follows that one can have a more or less clearly defined concept of $\mathrm{X}$, reflecting the level of understanding one has about that object at any given time. This seems to apply to both general and particular concepts.

It has already been argued that one must possess a sense or understanding of the self to be a subject. Gennaro's theory about the four levels of self-understanding seems to suggest that selfunderstanding itself comes in degrees, and as such, it makes sense to say that one can have a 
more or less sophisticated concept of the self. This is Gennaro's position on the matter, ${ }^{83}$ which seems to be right. In keeping with this position, we can claim that it is probable that many nonhuman animals possess concepts of the self, albeit to varying degrees. For those who believe that to possess a concept of something means that that concept must be of a formal and abstract nature, then it cannot be said that many non-human animals possess self-concepts.

In their accounts of self-awareness and self-consciousness, it seems that Chan and Harris, Gennaro, and DeGrazia all have something very similar in mind- namely, the degree to which one is aware of oneself. Both of these notions refer to the space in one's phenomenal field wherein one experiences, or can experience, the self, either directly or indirectly. In DeGrazia's account of self-awareness, he discusses the self's relation to itself (bodily and introspective selfawareness) as well as its relation to others (social self-awareness). In this sense, self-awareness describes an understanding of the self that arises out of its relation to external things. In contrast, self-consciousness describes the ability to possess a concept of "I," however complex.

Regardless of how one formulates the ability to distinguish and recognize the self, being a subject rests only on having a rudimentary understanding of the self, such that one can distinguish oneself from others and their environment, to see oneself as the centre of their experiences, and be able to identify sensations as one's own. Being a being who has a sense of self, who is someone rather than something, is a special feature that gives rise to moral duty on the part of moral agents.

83 Rocco J. Gennaro, “Animals, Consciousness, and I-thoughts,” in The Philosophy of Animal Minds, ed. Robert W. Lurz (New York: Cambridge University Press, 2009), 190. 
In sum, subjectivity is comprised of multiple components and cannot be reduced to a singular trait. Subjectivity is a fabric made up of consciousness, psychological unity, and selfawareness. Psychological unity and consciousness comprise the foundational component of subjectivity -the architecture that makes experience possible and the phenomenal experience of being alive that comes out it, respectively. Self-awareness refers to the space in one's phenomenal field wherein one experiences, or can experience, the self, either directly or indirectly. While many subjects may be self-conscious, i.e. they possess an abstract concept of "I", it is not required to have subjective experiences.

The first of three dimensions of my conception of persons - the capacity to experience subjectively - has now been presented. Having set the ground work, I will now discuss the other two dimensions: emotions and interests. While the discussion of emotions and interests is shorter than the discussion of subjective experience, they are not less important. The capacity for having emotions and interests is founded upon and made possible by subjectivity. The relationship between being a subject and having emotions is that emotions serve an adaptation function aimed to preserve the self by improving one's understanding of one's surroundings. The relationship between being a subject and having interests is a little more enmeshed. It seems that by virtue of being alive, a being must have some interests in some sense of the word, whether conscious or not. For instance, we could say that, in a sense, a plant has an interest in being alive by virtue of it possessing functions that keep it alive. But in the case of subjects, additional and deeper senses of the term interests also begin to apply, such as a subject's interest in finding a mate or in being autonomous. I will now discuss emotions and interests in turn. 


\section{Emotions}

I do not believe it is necessary to give a full account of the nature of emotions, since it would be beyond the scope of the thesis to do so and because only a few features of emotions are necessary to articulate for my purpose. ${ }^{84}$ The important thing needing to be said about emotions for my purposes is that they are temporary felt mental states that are (or at least often can be) interpretations of one's surroundings. Emotions are what make experiences positive or negative rather than one of indifference, and as such, they are what allows a being (in part) to prefer certain circumstances over others. In this sense, emotions may also further drive a being to avoid pain and harmful situations and to seek and desire pleasurable experiences. It is fairly uncontroversial that many non-human animals have an at least basic repertoire of emotions, such as those associated with basic survival functions like fear, contentment, and anxiety.

Physical sensations such as pain, pressure, and hunger, are informational in nature. They are usually completely automatic, and they tell us whether our physical integrity is in jeopardy. Emotions are not the same as these kinds of sensations and, while they can be informational, they are not informational in the same way as these physical sensations. Emotions have a "felt" quality and are typically experienced as temporary mental states (or fleeting moments) rather than as physical states, although intense positive and negative emotions can be experienced alongside with physical sensations, such as feeling butterflies in one's stomach.

Emotions are interpretive in nature. Feeling fear is to interpret a situation as threatening and experiencing anger is to interpret a situation as unfair. Thus, to have emotions is to have a

84 For fuller accounts of emotion that also discuss emotion in non-human animals, see Roberts, The Sophistication of Non-human Emotion, and Darwin, The Expression of the Emotions in Man and Animals. 
perspective on reality and implies the existence of an, at least, semi- rich mental life. In his article entitled "The Sophistication of Non-human Emotion," Robert Roberts proposes that emotions are "concern-based construals" that consist of two features. He claims that:

The paradigm human emotions are events of receptivity structured by a synthetic unity of "factual" and "evaluative" attribution. Thus, emotions ascribe some character or other to the situations they are about, and this character is both "descriptive" and "evaluative" (concern-based - a matter of care or interest to the emotion's subject). ${ }^{85}$

Thus, emotions regard a particular situation while simultaneously making a judgement about that situation. This seems to apply just as well to non-human animals as it does to humans. In experiencing an emotion, we are perceiving a situation as threatening, welcoming, or what have you. The situation, or fact, aspect of the experience is tied with an interpretation, or evaluation, of the situation. For Roberts, the ability to have thoughts is not required to have emotions. In both humans and non-human animals, these evaluations are often automatic in that they occur before one can form conscious thoughts about the situation. He claims that thoughts are something like an object of conscious awareness that can be manipulated and brought to mind in the absence of the original stimulus that created it. Although an emotion can become an object of conscious awareness and be analysed, at its root it is a kind of perception. ${ }^{86}$

Emotion gives richness, depth, and meaning to our experiences. Beings who have emotions have a unique subjective perspective that is made fuller by the experience of emotion. Such beings are not simply being in the world; they are also making a kind of assessment about reality. While emotions may be generated unconsciously, they usually become conscious, felt

85 Roberts, "Non-human Emotion," 218.

86 Roberts, "Non-human Emotion," 223-224. 
and thus part of one's phenomenal field. Having an even basic repertoire of emotions means that when one's interests are frustrated, this interest frustration becomes a felt, negative experience rather than an experience regarded with disinterest. It is this "enhancement" of our experiences (the presence of emotions) that makes it possible for a being to perceive that they are being harmed, and particularly to experience mental rather than simply physical distress.

\section{Interests}

Bernard Rollin defines interests as "conditions without which the creature, first of all, cannot live or, second of all, cannot live its life as [the type of creature it is] nor fulfill its telos." "87 By "telos," Rollin means flourishing in the Aristotelian sense, understood as realizing one's nature, function, and way of being. Although he makes a distinction between survival interests and telos-fulfilling interests, the notion of telos-fulfilling interests encompasses survival interests, since the fulfillment of basic survival interests are necessary to be the kind of being one is.

Without considering a creature's interests, we do not capture all the ways in which a creature can be harmed. Rollin gives the example of painlessly killing a human being. If an immoral action is defined as one that causes pain or suffering, then how do we account for our intuitions that killing a human being painlessly is still wrong? To be a creature of moral concern

87 Rollin, Animal Rights and Human Morality, 100. 
is not only to have the ability to feel pain, but also to be the kind of being that can have its needs for living go unfulfilled and the expression of its nature thwarted. ${ }^{88}$

Rollin makes an important conceptual distinction between having a mere need and having an interest. He claims that anything can have a need, in that everything is such that there are certain things required for it to function or exist (for example, a car requires gas and a computer requires electricity). Rollin gives the example of a car. It does not matter to the car itself if we fail to maintain it and it degrades. In cases like cars, and other inanimate objects, providing or failing to provide what is necessary to maintain its structural and functional integrity is not something that the car is aware of. More than this, failure to maintain the car doesn't have a huge impact on its overall integrity. For things like cars and machines, there is no way of being that is intrinsic to them - their purpose is not found inside them or in nature, but through human invention. ${ }^{89}$

For both cars and many sentient creatures, or in my terminology, subjects, we can objectively measure what they are lacking and what may be required to bring them back to full functioning. However, only subjects experience a loss of integrity when there is a failure to acquire their needs, since their purpose, or telos, is intrinsic rather than extrinsic. Thus, what makes a need an interest is that there is a being to whom the fulfillment of such needs matters. ${ }^{90}$ This awareness of one's needs, however rudimentary, and the struggle that exists to keep on

88 Ibid., 100-101.

89 Ibid., 100-101.

90 Ibid., 101-102. 
acquiring these needs, is of moral significance, since moral agents can interfere with another's ability to fulfil their interests. ${ }^{91}$

There are many indications that a being's interests may not be being fulfilled, such as the expression of anxiety, boredom, and anger. Thus, language proper is not required for a being to express (consciously or unconsciously) that their interests are not being met. ${ }^{92}$ This is clear in the human case where we can observe from someone's facial expression that they are sad or distressed, or can tell by the way they are sitting that they are anxious and on edge. These same non-linguistic cues are what we can look for in non-human animals to tell us about their internal states.

Rollin claims that the most obvious and basic interest a being has is the interest in continuing to live. This interest is shared by all sentient creatures by virtue of their being alive and sentient. Other interests are specific to, or typical of, particular species. ${ }^{93}$ For example, it is good for the health of a bird to be able to fly and thus space for flight is in the interest of birds. However, cats do not have this interest, but they do have an interest in engaging in play and hunting behaviours. The inability to play, or get sufficient exercise, is now known to cause obesity and boredom in domestic cats. Acquiring the knowledge of what is in a certain species' interest is a matter of studying both their biology and behaviour.

Interest frustration represents one of the most basic ways in which one can be mentally rather than merely physically distressed. Interests, such as being part of a social group and not

91 Ibid., 99

92 Ibid., 102.

93 Ibid., 118. 
being confined to small spaces, are interests that, when frustrated, can produce physical discomfort as well as negative emotional states such as anxiety and loneliness. In chapter four when I discuss what may indicate that the interests of captive non-human animals are not being met, I will discuss the notion of suffering, which can be caused by continual interest frustration.

In sum, interests are key considerations in determining how to treat persons, human and non-human. We can distinguish between interests that are necessary for one's basic survival, and those that fulfill and express one's telos, although the notion of telos-fulfilling interests encompasses basic survival interests. When we consider such interests, it is clear that pain alone is an insufficient criterion to use to determine if we may be harming a being. Persons can be harmed when we do things like confine and isolate them, starve them, remove them from their family units, and prevent them from engaging in natural behaviours. Such actions constitute direct harm since interests are inseparable from the individual, and, as such, is what makes the harm personal in nature. Next, I will discuss why my conception of personhood has many strengths over traditional conceptions.

\section{Advantages of my Account of Personhood}

My account of personhood has several advantages in general and over traditional accounts. Firstly, in understanding many characteristics as ones that appear to vary in degree rather than in kind across species, I am remaining consistent with the current understanding of the implications of evolution. Any philosophy that insists there is a fundamental difference between the subjectivity of humans and non-human animals is not consistent with scientific findings and ignores or does not take seriously the wealth of information science has provided us. Of course, 
humans and non-human animals differ significantly in aspects such as the reach of their cognitive capacities and the complexity and role of culture, among other aspects, but when it comes to basic needs and natures, they are not fundamentally different. The differences that do exist between human persons and non-human animal persons are relevant for practical concerns, but are not morally relevant in that both groups will possess the characteristics required for personhood.

Second, I believe my conception of persons is more faithful to the ultimate purpose of identifying persons - namely, to identify beings who are worthy of special moral consideration. Beings who can participate in the moral community and are moral agents are a distinct category from those beings who are of moral concern. In making this distinction, I am able to make the threshold for classification lower and thus more inclusive. It also allows us to get back to basics so to speak, to not have to get lost in debates about complex cognitive abilities that we know less about in the non-human animal context.

Third, my conception is both quantitatively and qualitatively less onerous than many traditional conceptions. That is to say that my conception requires the possession of fewer characteristics to be classified as a person, and the degree to which a being must possess those characteristics is lower. Because of this, my conception is more inclusive and many of the exceptional cases that are seen as problematic are no longer problematic, since many of these individuals would be considered persons on my account.

Lastly, my account identifies and defines the necessary characteristics for personhood - ones that constitute the minimum threshold for classification. This makes the actual application of the theory much easier since all relevant characteristics, and the degree to which they are required, are fully defined. Working with a metaphysical conception of persons, rather than a purely moral 
one, is likewise more conducive to practical application, since the characteristics that define a person on my account are empirically verifiable. In consulting scientific literature, I am able to work with and present the most accurate, up-to-date understanding of the minds and behaviours of non-human animals.

The fact that my conception is one that can be applied is particularly valuable since identifying persons is an important, real life issue. In the following chapter I will discuss ways in which we might apply my conception of personhood. It is not my goal here to articulate a full and ready plan, but the discussion is rather meant to show what taking up my conception would likely entail. To this end, I will discuss the moral and legal implications of my own conception of personhood, which kinds of rights non-human animal persons may have, which kinds of obligations we may have to different groups of non-human animal persons, and how the confinement of non-human animal persons would be unethical in most cases. 


\section{Chapter 4}

Practical Application and Policy Implications

The general goal of this chapter is to discuss the potential application of my conception of personhood and some policy implications that may arise out of its application. There are three main sections of this chapter. The first section discusses the moral and legal or normative implications of my conception of personhood in general, which kinds of obligations we may have to wild, liminal, versus domestic non-human animal persons, and what legal rights they may have. This will capture part of the legal sense of the term "person" as it applies to my conception.

The second section discusses the lives of captive non-human animal persons. In discussing confinement, I will be focusing on the context of zoos and aquariums since these institutions, when well-funded, are typically believed to provide the highest standards of care for confined non-human animals. ${ }^{94}$ Here I try to understand what it is like to be a captive in a zoo from a non-human animal's point of view, touching on the themes of liberty, autonomy, dignity, integrity, and physical and mental well-being.

The third section challenges the justifications for and supposed benefits of zoological institutions, discussing their contributions to research, education, and conservation. Here I suggest that there seem to be viable alternative ways to fund research, teach the public, and restore endangered populations. In addition, I will also briefly address issues regarding

94 Hereafter, when I use the term "zoological institutions" I am referring to zoos, traditional aquariums, and aquarium theme parks like SeaWorld. For the most part, when I speak of zoos, what I say will apply to all zoological institutions. 
authenticity in the zoo experience, discussing the objectification of individuals on display and the limited, inauthentic nature of controlled, structured encounters.

\section{Moral and Legal Obligations to Non-Human Animal Persons}

What makes a being worthy of personhood status on my account is the capacity to be harmed directly. In the previous chapter I claimed that subjectivity, or being a subject, is what makes one experience things directly and personally. A being that has interests can be harmed when we do not fulfill their interests when they are in our care, and having emotions makes it possible for such a being to experience negative, unpleasant states when these interests are frustrated.

Determining which beings are persons, and which are not, is important since persons are treated differently than non-persons. Persons are treated with higher regard in legal matters, are given more respect in social matters, and may experience a higher quality of life because of this respect and acknowledgement. Legally speaking, persons are usually accorded rights and come under the protection of the law. In the event that their rights are infringed upon, action can rightfully be taken to seek justice. Socially, they are understood and treated as who's rather than things and their interests are respected.

There are both moral and legal or normative implications of my conception of personhood. Thus, the term "person," in this case, specifies a certain kind of being to whom we have moral obligations, and serves as a basis and justification for making legal claims. The main focus of this thesis, so far, has been on describing the kinds of beings to which we have moral obligations. I will now focus on the legal or normative implications of this definition. 
To begin, I will discuss issues with the property status of many non-human animals and how one cannot simultaneously be a person and someone else's legal property. In the next subsection, I will discuss the difference between positive and negative obligations and the moral relevance of our relationship to various non-human animal groups (domestic, liminal, and wild). In the final sub-section I will discuss an interest-based account of rights for non-human animal persons.

\section{Persons Cannot be Property}

Deeming many non-human animals as persons will certainly affect how we interact with them. The most common way we interact with non-human animals is to use them as resources for food, clothing, entertainment, and research. It seems that most of the conventional ways we use non-human animal persons are not compatible with a respect for their personhood. For most conventional uses, we confine non-human animals in order to use them, the effects of which will be discussed in section two of this chapter. Some of the ways we use non-human animal persons would have to cease on principle. For example, we could not kill them for food. Other ways in which we use them may only require a change in conventional practice. For example, it may not always be harmful to a dog to be used for a film. The length of time he is needed, how much training needs to be done and what training techniques are used, what kind of actions he must do, etc., will contribute to an assessment of whether or not his interests are being respected. One thing that is certain is that one cannot simultaneously be a person and be someone else's legal property. 
Currently, most of the non-human animals we use as resources and keep as companions are considered our property. Abolishing the property status of non-human animal persons seems required if we are to truly respect their important interests and status as persons. Laws have been passed that are intended to reduce the suffering non-human animals experience as incidental to their use. However, Gary Francione claims that these efforts have not resulted in any significant protection of non-human animals, and their failure is mostly due to the fact that, as property, their interests always come secondary to the property owner. ${ }^{95}$

Francione points out that when a conflict of interests arises between a property owner and their non-human animal property, the non-human animal's interests are usually outweighed because of the structure of property ownership itself. The laws regarding the treatment of nonhuman animal property do not demand a particular standard of care be met. The infliction of extreme suffering is acceptable when it is believed that it will ensure that the non-human animal property will continue to be useful for the property owner. ${ }^{96}$

For example, it is the position of many circuses that training elephants to perform requires the use of physical punishment. Training methods include intimidation, whipping, and hooking (a sharp pointed hook to apply painful pressure behind their ears). In a different context, this kind of treatment would constitute cruelty but because it is done within the accepted practice of circus performance and the elephants are property of the circus, this is not a violation of anticruelty laws. It is only when the imposition of suffering is not part of the typical use of a nonhuman animal that it becomes questioned. In addition to this loophole, there are many species

95 Francione, Animals as Persons, 38.

96 Ibid., 39. 
that are completely exempt from anti-cruelty statutes. A stunning example of this is the federal law in the U.S.A. regulating non-human animal use in biomedical experimentation called "The Animal Welfare Act.” Rats and mice are the most used non-human animals in biomedical experiments yet they are exempt from consideration in this act. ${ }^{97}$

If the non-human animals we use were deemed persons, then they could not also be considered our property. Along with the reasons Francione so articulately presents, this is necessary because respect for persons must entail a respect for their interests, both their basic survival interests (which would mean we cannot kill them for food), and their species-specific interests that make them who they are. Abolishing the property status of non-human animal persons seems like one of the first steps we must take if we are to consistently apply my conception of personhood. The next step seems to be deciding what kind of obligations we may have towards different groups of non-human animal persons.

Differentiated Responsibilities to Wild, Domestic, and Liminal Non-human Animal Persons

Philosophers distinguish between two main categories of rights and obligations: positive and negative. Negative obligations or rights typically refer to actions that are impermissible. They forbid another from acting a particular way towards you, and the aim of such restriction is usually to prevent the loss or violation of certain interests, such as interests in continued life, not being tortured, and not being enslaved. These kinds of obligations are generally about noninterference. In contrast, positive obligations and rights typically refer to actions that one must do

97 Francione, Animals as Persons, 39. 
for another. Sometimes these arise out of contractual agreements. They aim to provide things that are beneficial to one's well-being, such as food, services, and decent living conditions.

It appears that our relationship to certain non-human animal persons should impact which kinds of obligations we have towards them. I have in mind those situations in which we have made them dependant upon our care for survival, such as companions and non-human animals in zoos. Philosopher Clare Palmer claims that we have more obligations to domestic and captive non-human animals than we do to wild ones. Palmer points out that there are many different ways one can define what constitutes being wild or domestic. For instance, wildness can refer to the location a non-human animal lives in (away from significant human interference), or it can refer to a non-human animal's disposition as unaccustomed to human contact, or it can refer to a non-human animal (or species) whose breeding practices have not been interfered with by humans. Palmer understands domesticated non-human animals as those whose breeding practices are under the control of humans (at least in part). ${ }^{98}$

For the sake of this discussion, I define wild individuals as those who live in their natural environments away from significant human interference. I define domestic individuals as those who are directly dependant upon humans to meet their survival needs due to human interference with their lives. This would include all non-human animals who are kept confined, either temporarily or permanently. I define liminal individuals as those who are somewhat caught in the middle of these two categories. Liminal individuals are those who are indirectly dependant upon humans for their survival needs. This includes those wild non-human animals whose habitats we

98 Clare Palmer, "The Moral Relevance of the Distinction between Domesticated and Wild Animals," in The Oxford Handbook of Animal Ethics, ed. Tom L. Beauchamp and R. G. Frey, 701-725 (New York: Oxford University Press, 2011), 702. 
have destroyed to the point that they are no longer viable homes, individuals who are of a domesticated species like cats and dogs but who are feral, and those who have adjusted to life amongst human activity, such as squirrels, raccoons, and rats. I will first discuss our obligations to wild individuals, and then discuss domestic and liminal individuals.

The most common way in which we seem to interact with wild non-human animals (other than hunting) is by studying them or interfering with their activities or their environment. This involves going into their natural, wild habitats to observe, study, or monitor them, or make changes to their environments, such as erecting fences to prevent grazing in farm lands or stationing guards to protect endangered species from poachers. This may or may not involve direct interaction with humans. The necessity of the interference and the benefit to those disturbed must be considered on a case by case basis and be evaluated in a new light. For instance, would it be permissible to tranquilize endangered rhinos to provide medical care for them and ensure they continue to breed? Or to permanently insert GPS trackers under the fin of an orca if it means getting valuable information about how to care for those populations?

It is beyond the scope of this thesis to fully answer such questions. But it does seem like we would at least have negative obligations to wild non-human animal persons. It seems we should have some positive obligations to wild species whose habitats we have destroyed since we have significantly interfered with their ability to fend for themselves and live well. Although these individuals may have once been wild, the effects of human influence may make these individuals liminal.

Palmer claims that when we have put non-human animals in positions of vulnerability and dependence, we have special obligations to care for them based on this relationship. Taking up her position, then we also have positive obligations towards species who have been 
selectively bred to take part in our lives, such as domestic cats and dogs. It is difficult to say how well domesticated cats and dogs would do as a species if we stopped bringing them into our homes. We know from statistics about feral cats and dogs in cities that they do not seem to experience as good health and as long a life compared to those who live in human households. Placing them in the wild (away from human interference) and allowing them to raise young in that environment may be the only way to tell if they could survive without our assistance. Whether this would be a justifiable thing is questionable.

It seems right to claim that individuals who have been placed in human homes, zoos, aquariums, and like situations of confinement, are directly dependant upon humans to care for them. Similarly, we can say that species who have selectively been breed to be "domesticated," such as cats and dogs, also have some dependencies. Such "domesticated" individuals who are feral may be indirectly dependant on humans for their survival needs, which would make such individuals liminal. The positive obligations we have towards liminal individuals would be more numerous and substantial than the obligations towards wild individuals but less numerous and substantial than those "domesticated" individuals that are accustomed to life in a human home.

Non "domesticated" species (those whose natures have not been tampered with by human interference with breeding practices), that we bring from the wild into captivity, such as tigers, are also owed positive rights. The amount of time the tiger spends in captivity will affect their ability to fend for themselves should they be placed back into the wild. If the tiger was a captive for a very short time, it is likely they will not develop a dependence, and upon their release we may not have further positive obligations towards them. However, those who are captive for longer periods of time will require assistance to live even if let free. The purpose of many sanctuaries is to account for such common situations. Thus, one's former status as wild, 
domestic, or liminal becomes irrelevant in the context of confinement since being confined means that one is totally dependant upon others for care. We have negative obligations and many positive obligations towards captive non-human animal persons.

In sum, we should have a legal obligation to always uphold negative rights to wild, domestic, and liminal non-human animal persons. In the case of domestic and liminal individuals, we also have an obligation to uphold positive rights when applicable. Because we have contributed to the dependency of many domesticated species like cats and dogs, they should have more positive rights than wild or liminal individuals. And for those individuals who are typically considered a wild species but find themselves in our care, such as many individuals in zoos, they likewise have many positive rights that their wild counterparts do not. Now that I have discussed our differentiated responsibilities to wild, domestic, and liminal non-human animal persons, I will elaborate on the nature of the legal protection to which they are entitled. Nonhuman animal persons, like human persons, should be ascribed legal rights.

\section{Interest-based Rights for Non-human Animal Persons}

The idea that non-human animals could have rights is not new. In their influential book, Zoopolis, Sue Donaldson and Will Kymlicka advocate for an interest-based account of rights for non-human animals. ${ }^{99}$ They highlight an important distinction between the way the term "animal rights" has been commonly taken up and the proper sense of the term. They say that sometimes those who believe we need more limits on our use of non-human animals, or think that non-

99 Sue Donaldson and Will Kymlicka, Zoopolis: A Political Theory of Animal Rights (New York: Oxford University Press, 2011). 
human animals have a "right-to" something, are called animal rights theorists. However, the true sense of the term, the way in which Donaldson and Kymlicka use it, refers to the view that nonhuman animals should have inviolable rights. ${ }^{100}$ Having inviolable rights means that no matter how much good would come out of violating your crucial interests, those interests cannot be violated. This is what separates a rights approach from utilitarian approaches like that of Peter Singer. Assuming a non-utilitarian perspective, if we are to be consistent in extending personhood status to many non-human animals, then we must also extend to them inviolable rights.

Usually inviolable rights consist of a basic set of negative rights, protecting the individual from being killed, enslaved, tortured, or confined. ${ }^{101}$ Donaldson and Kymlicka suggest that inviolable rights for non-human animals would include "rights to life and liberty, which prohibits harming them, killing them, confining them, owning them, and enslaving them. Respect for these rights rules out virtually all existing practices of the animal-use industries, where animals are owned and exploited for human profit, pleasure, education, convenience, or comfort.”102

For Donaldson and Kymlicka, justice is grounded in protecting vulnerable selves. ${ }^{103}$ For them, personhood equates to self-hood, and by virtue of being creatures with subjective experiences, such beings have interests. It is these interests that they argue should form the basis

100 Donaldson and Kymlicka, Zoopolis, 19. Although Donaldson and Kymlicka use the term "inviolable," they do not think such rights can be without exceptions. In keeping with their position, when I refer to rights, or inviolable rights, I am not suggesting they should be absolute. I will discuss such exceptions later in this subsection.

101 Ibid., 20.

102 Donaldson and Kymlicka, Zoopolis, 40.

103 Ibid, 32-33. 
for the extension of inviolable rights. ${ }^{104}$ Although there is still debate about whether there are circumstances that could allow for the sacrifice of one for the good of the many, in practice we still ascribe inviolable rights in this sense to humans. ${ }^{105}$ These existing inviolable rights for humans are also interest-based, and Donaldson and Kymlicka suggest that rights for non-human animals should be an extension of human rights. ${ }^{106}$

In order to recognize interest-based rights for non-human animal persons, we need to know the nature of the interests of each species in order to determine which rights are required and, perhaps, which rights may need to be articulated and affirmed for unique needs and interests. In the previous chapter I drew upon Bernard Rollin's understanding of the notion of interests, which he defines as "conditions without which the creature, first of all, cannot live or, second of all, cannot live its life as [the type of creature it is] nor fulfill its telos."107 For Rollin, what makes a being one of moral concern is that they have an intrinsic telos and an awareness of their needs, however rudimentary. It matters to such beings whether or not their needs are being met. To determine if a being's interests are being fulfilled, we can look at their behaviour and expressions, or natural signs, for indications of pain, suffering, anxiety, and more. An interest of one species may not be an interest of another. To determine which interests an individual nonhuman animal person has, we can look to the typical behaviour and life of others of the same species as a general gauge to learn about what is needed and liked. We can also monitor the

104 Ibid., 31.

105 Ibid., 22.

106 For further reading on the extension of human rights to non-human animals, see Cavalieri, "Are Human Rights Human?."

107 Rollin, Animal Rights and Human Morality, 100. 
individual's behaviour for signs of discomfort and distress to confirm whether our attempts to satisfy their interests have been sufficient. ${ }^{108}$

If we are to implement legal protection for non-human animal persons we need to know which interests are crucial for basic survival, and which ones are important to fulfill one's telos. These distinctions are not meant to create a hierarchy, but rather, to better understand how an individual will be affected if some of their interests are not being met. The satisfaction of interests that are related to the fulfillment of a person's telos are integral to that individual's healthy functioning. I agree with Rollin that beings who are worthy of moral concern are so, not simply because they can feel pain, but also because we can potentially frustrate or thwart the expression of their nature. ${ }^{109}$

Such interest frustration does not usually go un-noticed to the individual whose interests are being frustrated. Those who experience the frustration of either their basic survival interests or interests connected to their greater telos, are also likely experiencing negative emotions in response to their situation. While rights are usually not formulated simply in terms of avoiding negative emotional states, this is a significant aspect of my conception.

While we may be able to easily extend some human rights to non-human animal persons, there will be some rights that will be inappropriate to extend, and other rights that may be unique to non-humans that will have to be articulated and affirmed. Some existing (human) rights that may be inappropriate to extend to non-human animal persons include the right to vote, the right

108 When I discuss non-human animal persons who are confined in zoos and aquariums in the next section, I will discuss some behaviours we can look for that indicate whether interests have been met or not. Because of the wealth of studies on non-human animals already conducted, collecting this data to apply to real life situations is not an unreasonable task.

109 Rollin, Animal Rights and Human Morality, 100-101. 
to free speech, and the right to own property. But some basic shared legal rights do make sense, such as the right not to be killed and the right to be free from forced labour. To ensure that individuals are ascribed appropriate rights, we need to differentiate between humans and nonhumans while still understanding both groups as persons.

In the moral sense, all those, human and non-human, who qualify as persons should be ascribed personhood status and share a set of basic rights. But for practical reasons, a distinction can be made by separating the groups into "human persons" and "non-human animal persons" so that the process of ascribing rights and dealing with rights claims can be differentiated and made clear.

The inability of non-human animals to provide clear consent and enter into social and legal contracts will be a factor in determining which rights and privileges are appropriate and should be a consideration in our expectations of their behaviour. For instance, the inability to understand and agree to our laws means that non-human animal persons who, in effect, break laws should not be put in prison since these individuals are not moral agents and as such cannot be morally blameworthy. We could potentially find other measures that would be justifiable to prevent non-human animal persons from harming others.

These suggestions are illustrative and are meant to show that such a differentiation is possible and can resolve some practical concerns. Determining which rights are appropriate for which species would be an important next step in adopting a conception of persons that includes non-human animals. The last issue to be considered here is that we may have to make exceptions to these rights. 
While the rights I suggest for non-human animal persons are inviolable, they needn't be absolute all the time. Donaldson and Kymlicka claim that inviolable rights for non-human animals can come with exceptions just as is the case with human rights. For example, killing another human or non-human animal person out of self defense is permissible when necessary. If many non-human animals are deemed persons, then, at least in typical Western lifestyles, we would have to stop eating them, using them for clothing and entertainment, hunting them for sport, and more. There is no moral excuse to continue these practices. The only excuse we have to continue them is that we like the taste of non-human animal products, we like the look and feel of fur, we like the thrilling experience of seeing non-human animals close-up in person, and simply that our using them in these ways is familiar or common. But none of these reasons comes close to justifying the suffering and death of non-human animals that comes with these practices. Perhaps in non-Western contexts, or in extremely remote communities, it could be excusable (though perhaps not justifiable) to occasionally eat non-human animal products and use their fur for clothing should no other alternative be available. Such exceptions would have to be made in true life or death circumstances. ${ }^{110}$

In our modern developed Western world, the term "necessary" is used often to justify the confinement of non-human animals. In the next section, I move away from the topic of rights and move on to discuss what it may be like for a non-human animal person to be a captive - which is a circumstance which seems to involve the infringement of rights. There are many ways we can harm non-human animal persons. Aside from physically injuring them, we can also harm them

110 It is less clear how my conception will apply to cases like hunting in traditional cultures. It is beyond the scope of this thesis to consider all possible cases where exceptions may need to be made. 
psychologically by depriving them of their social or psychological needs and preventing the fulfillment of important interests. In doing so, we can make them feel anxious, afraid, bored, lonely, depressed, or angry. I will argue that confinement causes such harm.

\section{The Lives of Captive Non-Human Animal Persons}

The very nature of confinement seems problematic when considering the rights of persons. This section will explore the extent to which confining non-human animal persons is unethical. There are too many practices that confine non-human animal persons to give all of them treatment. So, I will discuss the two kinds of practices that provide the best living conditions (relatively) and have the highest welfare standards compared to all others: Zoos and Aquariums. ${ }^{111}$ I chose to examine zoological institutions because if it can be shown that confinement is problematic even in places where the conditions of confinement are considered the best we have, then the implication is that all our uses of non-human animal persons that involves confinement is unethical and cannot be justified. ${ }^{112}$ In this section I will discuss captive life for non-human animal persons, touching on the themes of liberty, autonomy, dignity, integrity, and physical and mental health.

111 Sanctuaries, conservation areas, and national parks are not included in this comparison since they do not confine non-human animal persons in a way that is comparable to zoos.

112 Many of the non-human animals we confine would likely qualify as persons on my account. Some species commonly found confined in zoos and aquariums that I think would qualify as persons include big cats, bears, wolves, deer, primates (orangutans, gorillas, macaques, etc.), goats, rabbits, kangaroos, giraffes, elephants, hippos, meerkats, eagles, owls, beavers, orcas, bottle nose dolphins, penguins, horses, and more. 
Most of the time when we confine humans it is meant as a punishment. When we send children to their room it is to purposely remove them from access to others and the rest of the house. When we send adults to prisons we do so not only to create a safer public sphere, but also because we think of a prison environment as undesirable especially in comparison to free life, and thus prison is experienced as a punishment. But being confined is not necessarily always a negative experience nor is it always harmful.

David DeGrazia evaluates the positive and negative dimensions of confinement for some non-human animals, and he asks whether there may be some instances where confining nonhuman animals can be justified. ${ }^{113}$ DeGrazia evaluates five commonly employed criteria by which we can judge a situation of confinement as just or unjust: 1) Whether one's basic physical and psychological needs are being met; 2) Whether life in confinement is at least as good as it would have been in the wild; 3) Whether the captive is being harmed unnecessarily; 4) Whether the quality of life experienced is better than not living at all; 5) Whether the captive is being respected.

DeGrazia also distinguishes between experiential well being and species-typical functioning. He claims that there can be cases where a non-human animal may not be able to participate in all the behaviours that typical members of their species engage in, but still not experience suffering. He gives the example of a kangaroo who lives in a zoo and does not experience some of the negative and unpleasant parts of life that are common in the wild, such as extreme hunger or lack of resources, bad weather, and injuries (that do not receive medical

113 David DeGrazia, "The Ethics of Confining Animals: From Farms to Zoos to Human Homes," in The Oxford Handbook of Animal Ethics, ed. Tom L. Beauchamp and R. G. Frey, 738-768 (New York: Oxford University Press, 2011), 741-753. 
attention). On the other hand, this confined kangaroo does not get sufficient exercise (and is likely unable to socialize properly). When we think about the experiential well being of this kangaroo, especially compared to aspects of a wild life, it seems that being in the zoo environment may be better overall. But when we consider the ability to perform natural functions, it seems that the kangaroo in the zoo is harmed in that he is prevented from expressing certain behaviours and that not all positive aspects of a wild life are present in zoo life. ${ }^{114}$

DeGrazia believes that both these dimensions need to be considered in an account of an animal's welfare, but acknowledges that the weight one places on the ability to engage in species-typical behaviour will strongly influence the outcome of the analysis. And DeGrazia himself cannot offer a strong conclusion for either keeping or releasing this kangaroo. ${ }^{115} \mathrm{I}$ believe that the issue of confinement is not always a straightforward issue, but the way DeGrazia has presented the kangaroo's situation is overly simplistic. He fails to consider many negative aspects of captive life and does not do a good job at trying to understand captive life from the kangaroo's own point of view. ${ }^{116}$

The importance of liberty and autonomy for persons is under-represented in this example. By liberty, I mean the ability to be free from barriers and constraints. By autonomy, I mean the

114 DeGrazia, "Confining Animals," 740.

115 Ibid.

$116 \mathrm{My}$ goal in this chapter of the thesis is to problematize captivity. While my focus is on the negative aspects of confinement, I do acknowledge that sometimes captive life can come with positive benefits that a wild life does not, just as DeGrazia points out. However, as will be articulated, the negative aspects of confinement are so harmful and numerous that it seems any benefits of captivity would be outweighed by comparison. 
capacity to make decisions for oneself and not be controlled by external forces. ${ }^{117}$ The importance of being able to behave the way we are designed and desire to behave is also underappreciated. This is an issue of integrity and dignity, which will be elaborated on in the next subsection.

By virtue of having emotions and interests, significantly or continually interfering with a person's ability to be free, autonomous, and dignified affect's the physical and mental health of that person. Non-human animal persons who are born into captivity have likely never been able to express their full repertoire of behaviours, and those who are captured from the wild suddenly find themselves unable to continue to be themselves. Since our bodies and minds are integrated, missing an entire dimension of life has a negative impact on our integrity, dignity, and holistic health. Perhaps preventing the expression of one behaviour from a species' repertoire would not cause harm, but for captives, multiple positive aspects of a wild life are missing.

In addition to the under-emphasis of the importance of liberty, autonomy, integrity, dignity, and health, DeGrazia's kangaroo example also fails to fully capture the nature of captive life. While it is true that worries about food acquisition, resource availability, and health care disappear when under the (proper) care of humans, it is also precisely these aspects of experience that breathe life into existence. And there are certain differences in experience between nonhuman animals born in captivity on the one hand, and those who are captured from the wild and brought to a zoo or aquarium on the other. Those born in captivity are more "tame," as they become accustomed to humans immediately. Those who lived a wild life have more difficulty in

117 I understand that the notions of liberty and autonomy are debated in philosophy and can have different connotations. It is beyond the scope of this thesis to provide a more thorough discussion of these notions and to investigate how other connotations could apply to the context of confinement. It is enough for my purposes to define liberty and autonomy as above. 
captivity, especially at first, because they had, up until their capture, been living full,

unencumbered lives. Even though being born into captivity is "easier" on a non-human animal, this does not mean that they do not suffer from the very things that cause a formerly wild nonhuman animal to suffer.

When all of one's basic needs are taken care of, there is not much left to do, and boredom is a common problem for confined non-human (and human) animals. Having one's basic needs always provided by others undermines one's ability to choose for oneself. In captive conditions, one cannot choose which food to eat, which other non-human animals to spend time with, who your sexual partner will be and how often you attempt to mate, which location you will live in and what features that home has, what your daily schedule will look like, and more.

For non-human animals who are predators, there is no possible way to sufficiently imitate the conditions for hunting. Hunting constitutes a very physical activity that keeps one fit, and the satisfaction and group bonding that comes from making a kill is absent. For social species, choice of group members is important. Often families stay together and travel in groups. But in captivity, this is not possible. Social groups are forced together and often consist of initial strangers. Merely being a member of the same species does not constitute a family or a community in much the same way as in the human context. The lack of family support and sometimes being unable to take refuge from others is harmful for social species. Likewise, not being able to engage in sexual behaviour can be frustrating and can affect one's temperament and overall well-being. For those non-human animals that the zoo keepers choose to breed, they are often not allowed to mate naturally (or simply don't know how) and instead they are subjected to artificial insemination. 
The habitat sizes provided by zoos are usually far too small to give non-human animal persons the space needed to resolve conflicts, to get exercise, and find solitude. For those species who have particularly large natural territories, travel great distances, or follow migratory patterns, the lack of space is especially distressing. The ability for non-human animals to hide from the gaze of the public has in recent years become of great concern, and many of the better resourced zoos have since included small areas in the habitats for them to hide. However, these "private" spaces are small and often do not even fully hide the non-human animal from view. In addition to almost always being seen and watching humans observe them, most of the nonhuman animal persons in zoos have much better hearing than humans, and the constant noise of gawking visitors prevents private spaces from being true places of solitude. The features of the habitats are also usually underwhelming and sometimes consist of fake rather than real plants, rocks, trees, etc. ${ }^{118}$

The effects of confinement can also go beyond the effects on individual captives. Many species have complex social structures, and when many members or key individuals are removed, the entire wild social group can become at risk. This has been observed in wild cetaceans (whales and dolphins). ${ }^{119}$ The lives of elephants are also very social and involve a lot of travel over great distances. In the wild, elephant groups take the form of a matriarch-centered cluster, with the females staying together for life and the males going off to other groups around age fourteen. Elephants are constantly moving and walking, traveling for up for 20 hours a day

118 It is important to keep in mind that these conditions are representative of the best zoos in the world. Many zoos are more like backyard petting zoos than proper institutions. The conditions in these zoos are much more impoverishing than in large, institutional zoos.

119 Lori Marino, "Cetacean Captivity," in The Ethics of Captivity, ed. Lori Gruen (New York: Oxford University Press, 2014), 29. 
over distances of up to fourteen miles. ${ }^{120}$ In a zoo environment, these fundamental aspects of being an elephant are completely denied. ${ }^{121}$

What is unique about aquarium theme parks like SeaWorld and Marineland is that, in addition to the issues of liberty, autonomy, integrity, dignity, and health that are present in zoos, many of the non-human animals in these parks are also forced to perform tricks. The contemporary social attitude towards circuses that use non-human animals in performances has begun to shift from positive to negative. One factor contributing to this shift is the release of several documentaries that tell inside stories about such institutions and expose previous media cover-ups. ${ }^{122}$

Although there is a difference between the lives of performing non-human animals in aquariums versus those in actual circuses, the quality of their lives in both contexts are extremely

120 Catherine Doyle, "Captive Elephants," in The Ethics of Captivity, ed. Lori Gruen (New York: Oxford University Press, 2014), 39.

121 There are many analogies that can be made between non-human animal confinement in zoos and aquariums and human confinement in prisons, such as the negative effects of confinement on captives. In an article entitled "Life Behind Bars," five currently incarcerated men describe their prison experience, mentioning things like: the difficulty of becoming accustomed to a structure of domination; being met with force when unreasonable orders are given and you show resistance; feeling like you're being stalked because of constant surveillance; never getting lasting moments of quiet or silence to reflect, think, or re-energize; having to choose (if the choice becomes available) between access to needed socialization in noisy dorms versus a bit more quiet time in lonely smaller cells; being unable to leave your cell for up to 23 hours a day; becoming dull due to insufficient intellectual stimulation and opportunity; and the inability to experience true intimacy and a loving touch. These difficulties apply just as well to the kinds of non-human animals confined in zoos, and touch on the themes of liberty, autonomy, dignity, and health. Although it is beyond the scope of this thesis to investigate the similarities between human and non-human animal confinement, this would be a fruitful area of enquiry.

122 See the appendix for examples of documentaries that have raised public awareness about the negative effects of confinement on non-human animals. 
low. Compared to non-performers, performing non-human animals must comply with the demands of training sessions and show schedules. The sheer size of cetaceans makes it particularly difficult to provide adequate space and the training techniques used are the same as those used in circuses, namely, positive and negative reinforcement, often involving punishments.

By the very nature of zoos and aquariums, their non-human animal captives cannot be treated in a way that fully respects their personhood. They must always be available and close-by for the viewing public. In both the human and non-human animal contexts, it is known that being kept captive for long enough often causes one to lose the ability to take care of oneself, creating a dependence on others once released from confinement. Half-way houses and non-human animal sanctuaries exist for this reason, in recognition that we have additional positive obligations to these individuals. ${ }^{123}$ Experiencing only slight restrictions on one's liberty and autonomy is unlikely to cause suffering, but the lack of space and inability to choose for oneself in zoos is extreme and typically lasts for a long time. Humans in prisons are able to use language to tell us about their experiences, and while captive non-human animal persons in zoos cannot do this, they too have been indicating to us that they are suffering. This is the focus of the next section.

123 An implication of my analysis could be that prisons are unethical and that we should not confine human beings. However, we also have to consider that humans exist as part of a society that has rules and arrangements. We (usually) understand these rules, we know which actions are punishable, and we know that going to prison is a possibility if we break these rules. In some philosophical perspectives, we, as moral agents participating in a society, have a contractual arrangement that is fair. Non-human animals' vulnerability and inability to give consent and fully understand their captive circumstances is what makes it particularly problematic to confine them, and is a relevant difference between zoo and prison confinement. 
Indications of Harm: Suffering, Death, and Indignity

One might rightly ask how we can determine whether or not certain conditions of captivity are actually causing harm to a non-human animal person. As in the human context, it is fairly obvious when a non-human animal person is experiencing severe pain or is acutely injured. While captive non-human animal persons may become injured or ill because of their confinement conditions or by physical conflicts, there is an additional kind of harm that can befall them that comes out of the continual inability to fulfill all of one's important interests. This kind of emergent harm is what I call suffering. As a general matter, we can use suffering as one guideline to tell us when we have significantly frustrated the interests of non-human animal persons.

Suffering is not the same as the sensation of physical pain, nor is it a simple emotion. While the experience of suffering can include the sensation of physical pain, at its core, suffering is a kind of mental state. One can be free from physical pain and still be suffering, although one can suffer due to prolonged physical discomfort. A state of suffering goes beyond the experience of intermittent moments of interest frustration, feeling pain, or being extremely afraid. For example, a wild female lion may experience several moments of interest frustration over a short time when there is a shortage of prey. The lion in this scenario is likely to experience hunger pains, exhaustion, anxiety, and pressure from other pride members to acquire food for the group. When a kill is made, these discomforts ease significantly. What separates this kind of scenario from a state of suffering is the temporariness of the interest frustration and the extent to which the period of interest frustration begins to affect one's well-being.

Suffering does not take place in a moment. Rather, suffering represents the mental and/or physical degradation that occurs in a being when their interests are constantly frustrated. Should 
one's physical, mental, emotional, and/or spiritual well-being become degraded beyond that which is expected in dealing with everyday life, one is suffering. In this sense, suffering is not an additional characteristic or quality that some beings possess, but in another sense, it does represent a unique, cumulative experience. The amount and duration of interest frustration that it takes to produce a state of suffering may vary from species to species, and from individual to individual.

Non-human animal persons who have interests are capable of suffering, and the capacity for emotion seems to play a vital role in making suffering a negative, felt state. As a mental state, the experience of suffering can at times be difficult to identify. However, there is a consensus that the demonstration of stereotypic behaviours indicates suffering, and many non-human animal persons in zoos and aquariums have exhibited these behaviours. The term "stereotypy" is applied to describe behaviour that is repetitive, purposeless, and sometimes harmful. Stereotypy can manifest differently across species and between individuals. Examples of stereotypic behaviour include self-mutilation, rocking or pacing back and forth, swimming or walking in circles, and excessive grooming, among others. It is well known that many non-human animals confined in zoos and aquariums manifest stereotypic behaviours, which are understood as indicators of psychological distress that is caused by captivity.

Many species we commonly find in zoos have demonstrated stereotypic behaviours and have manifested illnesses that are believed to be caused by confinement. Cetaceans (dolphins and whales) have demonstrated many stereotypies, including pacing, repetitive head bobbing, excessive submissiveness, unresponsiveness, hyper-sexual behaviour and excessive aggressiveness both towards each other and humans, stress-induced vomiting, and bodily selfmutilation. Captive cetaceans also seem particular sensitive to high levels of stress, and stress- 
induced illness are common, such as ulcers, gastritis, and cardio and psychogenic shock. ${ }^{124}$ Marino suggests that the conditions of captivity and its effects are the direct cause of cetaceans' general inability to live well in captivity. ${ }^{125}$

Elephants also have a known repertoire of illnesses and complications due to confinement. These include obesity, hyper-aggressive behaviour, painful and life-threatening foot and joint diseases, arthritis, musculoskeletal disorders, birth complications such as high rates of infertility and stillbirths, and stereotypies such as swaying, rocking, and head bobbing. ${ }^{126}$ And of course, we cannot exclude the fact that many non-human animal persons try to escape from their habitats as evidence of their not wanting to be there.

One inarguable indicator of confinement causing harm is early death. The expected life spans of captive non-human animals can sometimes differ from their wild counterparts, sometimes living longer and sometimes living much shorter lives, depending on the species. One particularly egregious example of early death is the case of cetaceans in aquariums and aquarium theme parks. Despite the practice of cetacean captivity and display beginning as far back as the 1860 's, the quality of life and life expectancy of captive cetaceans has remained very poor and short. When the practice first began, aquariums required constant "re-stocking" from the wild, and as the demand for these non-human animals increased, their absence in their natural habitats became a public and environmental concern, leading to regulations and bans on their capture. ${ }^{127}$ This lead to an increase in captive breeding efforts, but even now the infant mortality rate for

124 Marino, "Cetacean Captivity," 30.

125 Ibid., 32.

126 Doyle, "Captive Elephants," 50.

127 Marino, "Cetacean Captivity," 23-24. 
captive born cetaceans is often so high that the population cannot be maintained without bringing in more individuals from the wild. ${ }^{128}$ And not only are the death rates of captive cetaceans high, but there have also been reports of cetaceans committing suicide by holding their breath. ${ }^{129}$

Like cetaceans, captive elephants likewise experience shorter life spans than their wild counterparts, particularly female elephants, whose average life span can be half of that in wild environments. Elephants born in captivity have the shortest average life spans compared to wildcaught and wild elephants. And those who are born wild but get put into captivity have shorter average life spans compared to those who are born in and live their lives in the wild. ${ }^{130}$ And also like cetaceans, captive elephant populations are not stable and sustainable and require the importation of wild individuals. ${ }^{131}$ The current status of many wild elephant populations as endangered is an additional consideration in thinking about how ethical it is to keep elephants captive.

These indications that these non-human animal persons are being harmed by their captive conditions has not gone unnoticed by zoological institutions, and those that have the knowledge and resources have made attempts to improve the quality of life for their captives. In the early days of zoos non-human animals usually were kept in barren, cement cages. Eventually habitats were made to look more like natural habitats. This was slightly better for the non-human animals but was also done to provide zoo goers with a more "realistic" experience of higher educational

128 Ibid., 26.

129 Ibid., 24

130 Ros Clubb, Marcus Rowcliffe, Phyllis Lee, Khyne U. Mar, Cynthia Moss, and Georgia J. Mason, "Compromised Survivorship in Zoo Elephants," Science 322, no.12 (2008): 1649

131 Doyle, "Captive Elephants," 45. 
value. ${ }^{132}$ In recent years, zoos with healthier budgets have provided what are called "enrichments" to the habitat enclosures.

Enrichments can come in the form of structures, sounds, scents, items, or schedules that are believed to combat the known negative effects of confinement. For primates, a structural enrichment might consist of hanging multiple ropes from the cage ceiling to imitate branches and vines. This allows them to engage with their desire to be in the protection of trees and allows for a type of exercise that they cannot get in a traditional cage. To address their social needs, a zoo may schedule times where primates come together in a larger enclosure to socialize and play. For big cat species, enrichment might consist of placing a large hunk of meat in a tree and having them climb to get it rather than just putting the meat on the grass. This again mimics natural behaviours that tigers would do in the wild and gives them a slightly increased sense of autonomy. Tigers are also often given toys such as balls to give them an opportunity to play. ${ }^{133}$

These enrichments can certainly reduce psychological distress, but the effects of these efforts vary from species to species. In the case of chimpanzees, enrichment efforts in the form of habitat re-design aimed to reduce the stressful effects of being constantly surrounded by zoo goers have had a marked effect on their health and well-being. ${ }^{134}$ In the case of rabbits confined in research labs, enrichment efforts allowing them to live in social groups or have a high level of social interaction has had noticeable positive effects including a reduction of stereotypic

132 Stephen R Ross, "Captive Chimpanzees," in The Ethics of Captivity, ed. Lori Gruen (New York: Oxford University Press, 2014), 63.

133 "Big Cat Enrichment at Big Cat Rescue," Big Cat Rescue, accessed February 192017, https://bigcatrescue.org/enrichment/

134 Ross, "Captive Chimpanzees," 64. 
behaviour and decreased surgical recovery time. ${ }^{135}$ In contrast, for other species such as elephants and orcas, no level of enrichment has made a significant impact on their overall wellbeing.

While it is true that well funded zoos and aquariums provide the best care for captive non-human animal persons compared to other practices that involve confinement, and they have made big improvements, such as enrichments to many habitats, their standard of care is almost always insufficient to provide for all the needs and interests of non-human animal persons. ${ }^{136}$ This is especially true when we consider not only one's basic survival interests and the interest in liberty and autonomy, but also those interests that relate to the fulfillment of one's telos and the interest in being dignified. The discussion up until now has focused mostly on liberty, autonomy, and health. I will now focus on issues around integrity and dignity.

The ability to be the kind of animal one is, to fulfill one's telos, has been mentioned throughout this discussion but I wish now to bring it to the forefront. The concept of dignity aptly captures what it is to respect one's nature and individuality. The idea that dignity can apply to non-human animals is recent in the animal ethics literature. One of the earlier academic accounts of non-human animal dignity comes from Suzanne Cataldi, who begins with a description of her experience at a circus in Moscow.

135 Margo Demello, "Rabbits in Captivity," in The Ethics of Captivity, ed. Lori Gruen (New York: Oxford University Press, 2014), 79-80.

136 I acknowledge that there may be a few species who, if given more space and allowed to make more autonomous choices, may not be harmed by confinement. However, the issue remains of the necessity of keeping them captive at all, which will be discussed in the next section. 
Cataldi recounts the entrance to the circus arena where bears greet and take photos with the visitors. The bears were dressed in brightly coloured Elizabethan-style clown collars and had balloons tied to them. They appeared so tame as to make her wonder how many tranquilizers would have to be used to get the bears to be so compliant and dopey. Cataldi felt embarrassed for the bears, thinking about how obscene the collar made them look, and she felt bad for the bears in their unnatural state, being laughed at and made into a spectacle. One of the acts in the show itself also featured bears being made into a spectacle. In this act, a bear was dressed as a stereotypical 50's housewife, complete with frilly apron and a baby stroller. The bear was on her hind legs like she was wearing high heels, moving around the ring with the stroller clumsily and with difficulty. ${ }^{137}$

Cataldi suggests that these bears lacked "a certain dignity, a certain bear dignity that cannot be maintained, or ascertained, under this set of circumstances of this kind of circus performance. The bear's stature, its might, is tampered with. Tottering instead of towering, it's their threat to us that is tamed or trained out of them. No one is really afraid of the bears. All 'broken in' - broken inside- they are like puppets on strings, hollowed out, stuffed animals." ${ }^{" 138}$ It is not only the bear's autonomy and intrinsic moral value that is being undermined by their performance, but also the value of what it is to be a bear, and the importance of being able to live life as a bear. Traditionally, the concept of dignity tends towards a focus on autonomy and moral value, but Cataldi points out that even if the bears happened to be enjoying themselves and were not suffering, there is still an affront to their dignity in being made out to be totally unlike real

137 Suzanne L.Cataldi, "Animals and the Concept of Dignity: Critical Reflections on a Circus Performance," Ethics and the Environment 7 (2002): 106.

138 Cataldi, "Animals and Dignity," 107. 
bears. Preventing the bears from being bears and making them into spectacles is disrespectful of their natures and is debased entertainment. ${ }^{139}$

Dignity, etymologically, also refers to what is fitting and decent. Behaviour that is not becoming, indecent, or inappropriate is behaviour that does not align with one's status or individuality. Thus, not only is the ridiculous nature of the acts unfitting, but so are any circumstances that force the bears (or any non-human animal person) to be or act in a way that is inappropriate according to what is normal and fitting for them. In addition to being about one's behaviour, Cataldi claims that dignity is also about "how self-motivated, self-possessed, or selfcontrolled one's actions are. That is why treating or training animals past the ('breaking') point of their ability to resist undermines their dignity - their 'core' potential to thrive or flourish, to satisfy their (own) preferences, to be or become the entities they are..." ${ }^{140}$ Because dignity regards the ability to satisfy one's telos, dignity is morally relevant since undignified behaviour or circumstances often results in harm to one's well-being. ${ }^{141}$

Another way dignity can be understood and can have additional moral relevance is in consideration of the relational element of dignity. Building upon Cataldi's account of the circus bears and her analysis of dignity, Lori Gruen suggests that dignity is also inherently relational. By not respecting the dignity of captive non-human animals, it not only harms them, but also harms those humans who view them. Gruen suggests that when someone (a moral agent) fails to accurately perceive the moral worth of another and fails to treat them with dignity, they too become undignified. Thus, there are two ways in which a non-human animal can be undignified:

139 Ibid., 111.

140 Ibid., 114.

141 Ibid., 115-116. 
when they are unable to retain their integrity and be themselves, and when their indignity goes unrecognized by moral agents. Gruen claims that to aptly perceive when a non-human animal's dignity is being violated is good for us, since it exercises our moral agency and ethical capacities. ${ }^{142}$ There are also broader social implications of our failing to treat others with dignity, including a disruption of social harmony, and in cases where the undignified individual is also a member of a marginalized group, negative attitudes and prejudices are reinforced. ${ }^{143}$ This certainly applies to the non-human animals, who, as a group, are already undervalued and misunderstood.

Like Cataldi, Gruen believes that dignity is morally relevant, since respecting one's dignity is to respect one's telos. Neither Cataldi nor Gruen use the notion of integrity to describe what it is to be dignified, but it is a notion that is additionally useful. Both accounts highlight the importance of being able to be the kind of being one is, and, that being put into circumstances that prevent, mock, or make completely other one's way of being, is violating. The notion of integrity seems to capture this phenomenon well, for to have integrity is to be whole, undivided, unified, and cohesive. To have part of your being denied to you is to be less whole. While it may be impossible to literally remove an aspect of one's nature, it is possible to completely deny its expression or fulfillment. When we are denied our physical needs, such as food, this lack is experienced and felt. Likewise, when a bear is not given enough solitude or space to feel safe, she is unable to engage in other behaviours. In this sense, the bears at the Moscow circus and many of the non-human animal persons confined in zoos are incomplete. They lack integrity in

142 Gruen, "Ethics of Sight,” 239-240.

143 Lori Gruen, "Dignity, Captivity, and an Ethics of Sight," in The Ethics of Captivity, ed. Lori Gruen (New York: Oxford University Press, 2014), 234. 
that they are not able to be whole. They lack dignity in that they lack integrity, their telos and way of being is made impossible to fulfill by denial of liberty and autonomy, and that others are failing to recognize their indignities and inherent worth.

In sum, there are many indications to look for that tell us whether captive non-human animal persons are being treated well. Obvious physical indications of mistreatment, such as whining and limping, only tell us part of the story of their experience. Indications that tell us about their emotional and mental states, and the extent to which important interests are being met, are needed to ensure we are meeting our moral and legal obligations to non-human animal persons. Such indications include suffering, stereotypic behaviours, illness, early death, and the violation of dignity. The concepts of liberty, autonomy, integrity, dignity, and health are useful to help illuminate issues of confinement. Next, I will discuss issues with zoos and aquariums from a different, more anthropocentric perspective - namely, the extent to which they can be justified and how authentic the zoo experience is.

\section{Challenging the Justifications for Zoological Institutions}

Aside from being places of entertainment, well-funded zoos and aquariums usually also contribute to research, public education, and conservation efforts. Such accredited and wellfunded zoos and aquariums are able to partner with organizations and provide financial and administrative assistance; zoos provide education in the form of informational signage for zoogoers, host workshops for businesses and organizations, and participate in breed-and-release 
programs for endangered species. One cannot claim that these kinds of institutions do not have real benefits. However, there is room for criticism. ${ }^{144}$

The fact that good zoos and aquariums provide needed financial and administrative support for research is unchallenged. However, when we consider the quality of the lives of the non-human animal persons confined there, it is hard to justify keeping zoos around for this reason. Even if one takes a utilitarian approach rather than a rights approach, the suffering endured by non-human animal captives would seem to outweigh the benefit of supporting research. $^{145}$

From a rights perspective, like the one Donaldson and Kymlicka suggest, zoos cannot be justified on account of the number of important interests of their non-human animal captives that go unfulfilled. There are alternative funding sources that can be tapped to support research instead of the income that comes from zoo patronage. And should zoological institutions lose the ability to keep most of their non-human animal persons, this doesn't necessarily mean that they must close their doors and go out of business. While it would require creativity and some new attractions, existing zoos could transform into alternative centres for education and fund-raising.

Unlike the fact that many good zoos provide support for research, the claim that zoos and aquariums provide education to the public is dubious. While it is true that they provide informational signage for zoo-goers, the information is very limited. In addition, it is entirely up

144 For an article criticizing multiple aspects of zoos, see Jamieson, "Against Zoos.”

145 It is beyond the scope of this thesis to articulate what a utilitarian approach to personhood may look like. However, based on the fact that the interest humans have in researching nonhuman animals and public education are not vital interests, it seems we can claim that the violation of the interests of non-human animal persons, which are significant and vital, would outweigh those human interests. 
to the visitors to actually take the time to read these signs, not to mention whether or not the visitor is even interested in being educated in the first place. In an article criticizing zoos, Ralph Acampora states that studies conducted to evaluate the effectiveness of zoo's public education strategies show that zoo-goers are not significantly more knowledgeable than non-zoo-goers. ${ }^{146}$ Just as there are, or we can create, alternative funding sources for research, so too are there are other ways to create public interest in and promote increased knowledge of wildlife. This could include: improved school curriculums with the opportunity to go into wild habitats; the promotion and creation of more local and global eco-tourism opportunities for adults; an increased coverage of environmental and non-human animal issues in social media, news, and political agendas, and public service announcements.

The last purported benefit of zoos and aquariums is that they are sites for breed-andrelease programs, wherein endangered species are bred in captivity and released back into the wild in an attempt to conserve biodiversity and restore endangered populations. While these are noble causes, the success rates of these programs vary widely. For some species, these programs have proven effective, but for many others, such as carnivores generally, these programs have either not been successful enough to warrant the efforts, or they have been totally unsuccessful. $^{147}$

Contributing to the failure of breed-and-release programs is the fact that these non-human animals are raised in captive environments, which prevents them from developing the knowledge

146 Ralph Acampora, "Zoos and Eyes: Contesting Captivity and Seeking Successor Practices," Society and Animals 13 (2005): 73.

147 Kristen R. Jule, Lisa A. Leaver, and Stephen E.G. Lea, "The Effects of Captive Experience on Reintroduction Survival in Carnivores: A Review and Analysis," Biological Conservation 141 (2008): 361. 
and skills required for life in the wild. For example, deficits observed in carnivores that come out of these programs include inadequate hunting skills, inappropriate methods of socialization, and insufficient attentiveness to danger. ${ }^{148}$ Just as we may not require zoological institutions to attain funding for conservation efforts and provide education, we may not need them to continue breed and release programs. It seems it would better suit both captive and wild non-human animals if those raised in captivity had the opportunity to develop adequate "wild" skills, which may be better accomplished in a sanctuary, national park, or wildlife reserve setting.

In sum, zoological institutions do not seem necessary for, nor vital to the continuation of research, education, and conservation. There are many opportunities for reform, and other alternatives seem reasonable. The important interests of the non-human animal persons confined in zoos and aquariums cannot be fully met in the vast majority of cases, given the structure and practices of this kind of confinement.

Many of the positive obligations we would likely have towards these individuals could not be met, and perhaps even some of our negative obligations could not be met. Should we take an interest-based rights approach towards non-human animal persons, then keeping them confined in this way is both unethical and unjustified. What has been challenged so far in this section has been the foundational aspects of (well funded and accredited) zoos - those things that justify and perpetuate their existence. Next and lastly, I would like to challenge two aspects of the zoo experience that are more emergent rather than foundational. These issues come out of the structure of the zoo experience itself and may not be so obvious at first.

148 Jule, Leaver, and Lea, "Reintroduction Survival in Carnivores," 361. 


\section{Authenticity and Objectification in Zoological Institutions}

Aside from the issues around the justifications for zoos and aquariums and the well-being of their non-human animal captives, there are two main issues with the structure of the zoo/aquarium experience itself. The first issue is that the very nature of viewing confined "wild" non-human animals closes off the possibility of having the wild encounter people seek when they come to zoos. The second issue is that captive non-human animal persons can be made into spectacles and are objectified.

Ralph Acampora discusses these issues - some of the hidden realities of the zoo experience - in his article entitled "Zoos and Eyes: Contesting Captivity and Seeking Successor Practices." While he focuses on zoos, what he says here applies equally to aquariums and aquarium theme parks. Regarding this first issue, Acampora claims that zoo-goers do not receive the kind of "wild" encounter they seek when they come to a zoo. This is because there is no genuine aspect of the encounter left in a zoo since the non-human animals are accustomed to human presence, are prevented from acting naturally by the very nature of confinement, and are displayed in a simulated environment. ${ }^{149}$

The only aspect of the non-human animal persons being viewed that retains integrity is the look of their physical bodies. All other aspects, such as their tendencies, temperament, and general psychological nature, alter upon becoming a captive (sometimes temporarily but often permanently). In this sense, becoming a captive takes the very wildness out of them. By being confined, any animal (human or non-human) is not fully able to be themselves. And not only do we view somewhat false versions of non-human animals in zoos, but our watching and observing

149 Acampora, "Zoos and Eyes," 70-71. 
them is also disingenuous since the interactions are fixed, forced, and at the discretion of the human viewers. ${ }^{150}$ Lori Gruen claims that non-human animals cannot be perceived with dignity in a zoo setting. From the decorative habitats to the existence of the zoo itself, most of the zoo experience is made to satisfy our human desires.

I will now turn to the second issue with the zoo experience, that non-human animal persons who are captives can be made into spectacles and are objectified. I have already discussed being made into a spectacle when I presented Cataldi's Moscow circus experience. Acampora does a good job at describing how captive non-human animals can be objectified.

Acampora describes the zoo experience as pornographic since zoos and most pornography centre around what he calls "visive violence." 151 In both contexts, the objects of display are beings whose natures are concealed by their overexposure and are presented in a highly-mediated way. Both the non-human animal in the zoo and the porn star are representations or shadows of the real thing, purposely situated to highlight the exotic. They also both serve to satisfy desires and tickle fetishes regarding our fear of nature, having forbidden interactions, and both play up the dynamics of power, mastery and control. ${ }^{152}$ In watching the porn star or the non-human animal in the zoo, we turn them into visual spectacles, objectifying and consuming them.

Like Acampora, Gruen also claims that viewing non-human animals in this way reinforces both a false understanding of them, and a power dynamic of control and

150 Ibid.

151 Ibid., 71.

152 Ibid., $72-75$. 
domination. ${ }^{153}$ Animal rights theorists strive to shake this structure of power, but the structure of the zoo experience reinforces it. Donaldson and Kymlicka claim that the zoo experience can increase our sense of separateness from non-human animals. This separation, making non-human animals more of an "other" than they actually are, obscures the similarities we do have to them, and makes it harder to recognize non-human animals as fellow selves. ${ }^{154}$

To conclude, there are multiple issues with the institutions of zoos and aquariums, despite them being championed as the best examples of how to care for captive non-human animals. Despite this, such captive conditions are inadequate, especially if we recognize that many of the non-human animals confined there are persons. Keeping non-human animal persons captive in zoos and aquariums is additionally problematic when we consider the supposed justifications for these institutions and issues with the structure of the zoo experience itself.

With the growing ethical consciousness of the public and research about the abilities of nonhuman animals, there is momentum to improve the lives of non-human animals. I define persons as beings who are worthy of special moral consideration. They are subjects who have emotions and interests. As such, many of the non-human animals we interact with regularly would be classified as persons on my account. An account of the personhood of non-human animals, and the moral and legal obligations that come with this status, is one powerful way to keep this momentum. Acknowledging that many non-human animals are persons will ensure that these individuals are better protected and are given a chance to flourish and live their lives how they wish.

153 Gruen, "Ethics of Sight," 242.

154 Donaldson and Kymlicka, Zoopolis, 39. 
Concluding Remarks

\section{Summary of Main Points}

When we explore the reasons why non-human animals have not traditionally been considered persons, I find no compelling reasons to continue excluding them from the benefits of this privileged status. Changing the moral status of many non-human animals from things or property to persons is the first step towards ensuring that these individuals are treated in a way that reflects their moral significance.

In the first chapter of this thesis, I discussed the concept of personhood generally, setting the ground work for this change. There I claimed that definitions of personhood should be metaphysical, should clearly indicate which characteristics constitute a minimal threshold for classification, and should stick to the task of identifying which beings are worthy of special moral consideration, which is independent from identifying moral agents or those who can participate in a moral community. In addition to making a distinction between moral and metaphysical personhood, I also made a distinction between the physical and legal senses of the term "person." Physical personhood is assumed and is implicit in my account, and legal personhood, while not directly relevant, came into play in chapter four in discussing our legal obligations to non-human animal persons.

In chapter one I also discussed how to classify persons, touching on issues of identity and time, such as, how the characteristics required for personhood are not always present in the same individual, and how we may deal with exceptional cases. This chapter concluded with a discussion of the work of Eva Feder Kittay and Mary Anne Warren, who have very different views about what makes an individual morally considerable. 
The second chapter of this thesis challenged the inclusion of language and rationality as requirements for personhood. In doing so I speculated on the nature of language and rationality, discussing communication generally, natural signs, language proper, and how the ability to be rational can vary in degree. I claimed that language and rationality should not be criteria we use to identify persons because they are too demanding and set the threshold for personhood status unnecessarily and unjustifiably high. I characterized the view that language and rationality are morally relevant to personhood as an "exclusive" position. Here I discussed language ability and rationality in non-human animals as problematic for the exclusive position, and distinguished between the characteristics required to partake in moral decision making, or be a moral agent, versus the characteristics required to be morally considerable.

In chapter three I sought to articulate and defend my own conception of persons, as well as demonstrate that many non-human animals could qualify as persons on my account. I identify persons as beings who can be personally, or directly, harmed. Such beings are subjects that have emotions and interests, however rudimentary. ${ }^{155}$ To be a subject and have subjective experiences one must be conscious, self-aware, and have some degree of psychological unity (to have a connection between mental states that allows for a continuous experience). To be capable of emotions, such as anxiety, fear, and contentment, is to have a perspective on one's experiences and is what makes an experience positive or negative rather than one of indifference. To have interests (such as the interest in finding food and staying alive) is essential for determining which

155 Those that do not qualify for personhood even on my account are not necessarily relegated to the realm of "things." There are other frameworks and arguments for ensuring that nonpersons, whether non-human animal or plants, are respected and are not unnecessarily destroyed. An extension to my theory would include an account of how to treat non-persons. 
actions harm persons and which do not, since the frustration of interests can have negative effects on one's health, cause suffering, and be un-dignifying.

In the fourth and final chapter of this thesis, I examined some of the implications of my conception of personhood and how it could be applied. Here I considered the moral relevance of our relationship to different groups of non-human animal persons, distinguishing between wild, domestic, and liminal groups. I claimed that we have moral and legal obligations to non-human animal persons that vary in accordance to our relationship to them, and in any case, a rights approach that focuses on the importance of interests is necessary.

The last portion of chapter four focused on issues with confining non-human animal persons. I limited my discussion to zoos and aquariums since they are typically thought to provide the best captive conditions possible compared to other practices. The rationale for choosing these institutions was that if it could be shown that confinement in zoos and aquariums is problematic, my conclusion could be extended to other practices that clearly provide less adequate conditions. In my discussion of confinement, the themes of interest frustration, liberty, autonomy, integrity, dignity, and health surfaced as concepts that are especially useful for illuminating practices that harm non-human animal persons. Lastly, the justifications for and supposed benefits of zoological institutions were challenged, and I briefly discussed anthropocentric issues regarding objectification and authenticity in the zoo experience.

\section{Moving Forward}

If we begin to classify some non-human animals as persons, we will have to make changes in our day-to-day lives such as abstaining from eating meat, dairy, and eggs. We will 
have to find a way to move non-human animals out of zoos, aquariums, circuses, and farms and transfer them to sanctuaries. We will have to stop hunting for sport, stop forced breeding programs, and stop wearing fur, wool, and other non-human animal products. We will have to abolish their status as property, change the very infrastructure of agriculture, and alter our economic trading habits.

There is no moral justification to continue these practices in developed countries. The only excuse we have to continue them is that we like the taste of non-human animal products, we like the look and feel of fur, we like the thrilling experience of seeing non-human animals close up in person, and simply, that our using them in these ways is familiar or common. But these are not good reasons to justify the suffering and death of these non-human animal persons. Just because it was common practice for wealthier individuals to own human slaves did not mean it was an ethical practice. And just because women used to be considered unintelligent, irrational, and inferior to men does not make it true.

Abolishing institutionalized slavery was a huge task that changed many people's everyday lives. It had economic effects and slave owners had to change the way they conducted their businesses. Despite knowing that we would experience these practical difficulties, we abolished slavery anyway because we had a moral obligation to do so. In this sense, nothing is different from the non-human animal context.

Believing that we may one day reach the point where we seriously begin to deliberate altering the moral and legal status of non-human animals may not be farfetched. In 1949 Aldo Leopold described the extension of ethics as an "ecological evolution" that has already been 
unfolding. ${ }^{156}$ He points to the various ethical revolutions that have taken place, such as the changes in the social status of women, which proves that our understanding of what or who are of moral significance evolves over time. Leopold states that "no important change in ethics was ever accomplished without an internal change in our intellectual emphasis, loyalties, affections, and convictions."157

In this regard, I think Leopold is right. And there is evidence that such a revolution for a change in our moral conceptions of non-human animals is already underway. In addition to an increase in, and renewed vitality of, academic writing about non-human animals, there have been several media exposés and popular documentaries that have contributed to this ethical evolution. ${ }^{158}$ There have also been a few actual attempts to deem individual non-human animals as persons in court. The case of Sandra the orangutan is a recent, well-known example of such an attempt.

In December 2014, a court ruling made global headlines when a 29-year-old female Sumatran Orangutan named Sandra was deemed to be a non-human person and was to be recognized as a subject of rights. Sandra had spent the last twenty years in the Buenos Aires Zoo in confinement. The team who represented Sandra, the Association of Professional Lawyers for Animal Rights (AFADA), argued that she was unjustifiably confined, constituting a violation of liberty. To demonstrate that she was the kind of being whose liberty could be infringed, AFADA appealed to her ability to form emotional ties, to use reason, to feel frustration, to make

156 Aldo Leopold, "The Land Ethic," in A Sand County Almanac and Sketches Here and There, (New York: Oxford University Press, 1949), 1.

157 Leopold, "The Land Ethic," 5.

158 See the appendix for a discussion of such documentaries. 
decisions, and that she was self-aware and had a sense of time. AFADA filed a habeas corpus writ in her favour the previous November on the grounds that, as an individual likely possessing cognitive capacities, she was unjustly being confined. ${ }^{159}$ Should the ruling hold, Sandra will be sent to a primate sanctuary in Brazil where she will be able to exercise more liberty. ${ }^{160}$

Sandra is just one stunning example of humanity's growing appreciation for different forms of life. The fact that more and more humans, and now non-human animals, are coming into the sphere of ethical consideration demonstrates that our ethical categories are fluid and malleable. It is my hope that I have encouraged the reader to think differently about non-human animals and about what it means to be a being that is worthy of special moral consideration. Should we reconstitute our conception of personhood, the lives of many deserving non-human animals will be enriched, resulting in a more peaceful relationship between humans and nonhuman animals. The next step forward in such an ethical evolution is one that requires humility on behalf of humanity. We must begin to understand many non-human animals as subjects who have emotions and interests. We must come to acknowledge that many non-human animals are persons.

159 Habeas corpus is a motion requiring the individual in question to appear in person in court or to a judge. This is significant in the case of Sandra since non-human animals are usually not so directly involved in legal matters concerning them.

160 RT, “Argentine Court Extends Human Right to Freedom to Orangutan,” accessed March 12, 2015, http://rt.com/news/216551-orangutan-argentina-human-right/ 
Appendix

A number of notable documentaries have raised public awareness about non-human animal welfare issues. Here I will discuss two such documentaries, "Blackfish" and "Tyke: Elephant Outlaw," both released in 2015. These documentaries approach issues of non-human animal welfare very differently from academia, such as by raising public awareness, and as important contributors to the non-human animal rights movement, I wanted to give them mention here.

The documentary "Blackfish" does an exposé on SeaWorld, focusing on an Orca whale named Tilikum. It was released in 2015 and has been credited for the decreased patronage to places like SeaWorld, and is thought to have influenced the public outrage that led to SeaWorld ending their captive breeding program in 2015. The impact of this documentary comes from the story of Tilikum and his long-time trainer Dawn Brancheau.

Tilikum was captured in 1983 in the North Atlantic when he was 2 years old. In February 2010, Tilikum killed Dawn during a performance in front of a live audience. Tilikum had a history of aggressive behaviour towards previous trainers, including grabbing and nipping at them. In the wild there is no record of orcas harming humans, but in captivity there have been numerous incidents of aggressive gestures and attempted murder of the trainers from many different orcas.

The documentary also features an interview with two men, John Crowe, a diver, and Howard Garrett, an orca researcher, who were part of a team working to capture wild orcas for places like SeaWorld in 1970. They describe the experience emotionally. They recall that when they began surrounding the pod of orcas, the adults without babies went one direction to distract 
the boaters while the adults with babies went in another direction. Once catching up to and surrounding the pod with restraints, the team began removing infants. When the restraints were let down the adults didn't flee for safety, instead staying, and calling to the infants. John Crowe describes this moment, saying, "you understand then what you're doing,... I lost it, I mean I just started crying. I didn't stop working, I just couldn't handle it. It's just like kidnapping a little kid away from a mother... This is the worst thing I've ever done, is hunt that whale." Three whales died in this capture attempt, whose bodies were sunk.

Two former Seaworld trainers also describe similar emotional experiences. Their experience took place at SeaWorld itself when mother orcas and their young children were separated. One of the mothers, who was generally not vocal, stayed in the corner of the tank screaming and screeching when her baby was taken. In another instance, another mother orca began making loud screaming noises that was unfamiliar to the staff. The staff brought in experts to analyse her and found that she was using long range vocal noises that are used in the wild to try to locate her baby. John Hargrove, one of the observers of these instances says, "how can anyone look at that and think that that is morally acceptable. It is not. It is not ok."

Another documentary of a similar vein titled, “Tyke: Elephant Outlaw," was also released in 2015. It centers around an incident that happened in 1994 where an elephant named Tyke rebelled during a live circus performance in Honolulu, Hawaii. Tyke was captured from the wild as a baby in 1973 and was immediately put into the circus industry. During this performance, Tyke went on a rampage when she was brought into the ring, killing her trainer, injuring several others, and eventually escaping to the streets. Without any attempts to calm and control her, police chased her through the streets, eventually shooting her down completely in front of a crowd of emotional spectators. 
The event got a lot of live media coverage and resulted in the city of Honolulu holding a hearing to ban non-human animals in circuses in their city, but the notion was defeated by one vote. Despite policy remaining unchanged, these kinds of circuses were not welcomed back to Honolulu and never returned. Because spectators do not see the life of performing non-human animals and what happens behind the scenes, this well-documented incident gave humans a chance to see a different perspective, hailing Tyke as a martyr for the rights of non-human animals used in circuses. Likewise, Tilikum also became an icon for the welfare of captive cetaceans. These stories highlight differently the themes of liberty, autonomy, integrity, dignity, and health that have been discussed in chapter four. 
Bibliography

Acampora, Ralph. "Zoos and Eyes: Contesting Captivity and Seeking Successor Practices.” Society and Animals 13 (2005): 69-88.

Adams, Carol J. The Sexual Politics of Meat: A Feminist-Vegetarian Critical Theory. New York: Bloomsbury, 2015.

Aristotle. "Nicomachaean Ethics.” In The Basic Works of Aristotle, edited by R McKeon. New York: Random House, 1941.

Bentham, Jeremy. An Introduction to the Principles of Morals and Legislation. Edited by J.H. Burns and H.L.A. Hart. Oxford: Oxford University Press, 1982.

Big Cat Rescue. "Big Cat Enrichment at Big Cat Rescue.” Accessed February 19, 2017. https://bigcatrescue.org/enrichment/

Bryant, John, James Davis, David Haywood, Clyde Meikle, and Andre Pierce. "Life Behind Bars.” In The Ethics of Captivity, edited by Lori Gruen, 102-112. New York: Oxford University Press, 2014.

Cataldi, Suzanne L. "Animals and the Concept of Dignity: Critical Reflections on a Circus Performance." Ethics and the Environment 7 (2002): 104-126.

Cavalieri, Paola. "Are Human Rights Human?" In The Animal Ethics Reader, $2^{\text {nd }}$ ed. Edited by Susan J Armstrong and Richard G. Botzler. 30-35 New York: Routledge, 2008.

Chan, Sarah, and John Harris. "Human Animals and Nonhuman Persons." In The Oxford Handbook of Animal Ethics, edited by Tom L. Beauchamp and R. G. Frey, 304-331. New York: Oxford University Press, 2011.

Clark, Stephen R. L. “Animals in Classical and Late Antique Philosophy.” In The Oxford Handbook of Animal Ethics, edited by Tom L. Beauchamp and R. G. Frey, 35-60. New York: Oxford University Press, 2011.

Clubb, Ros, Marcus Rowcliffe, Phyllis Lee, Khyne U. Mar, Cynthia Moss, and Georgia J. Mason. "Compromised Survivorship in Zoo Elephants." Science 322, no.12 (2008): 1649.

Damasio, Antonio R. The Feeling of What Happens: Body and Emotion in the Making of Consciousness. Orlando: Harcourt, Inc., 1999. 
Darwin, Charles R. The Expression of the Emotions in Man and Animals. London: John Murray, 1872.

Davidson, Julian M. “The Physiology of Meditation and Mystical States of Consciousness.” In Perspectives in Biology and Medicine 19, no. 3 (1976): 345-380.

DeGrazia, David. "Self-awareness in Animals." In The Philosophy of Animal Minds, edited by Robert W. Lurz, 201-217. New York: Cambridge University Press, 2009.

DeGrazia, David. "The Ethics of Confining Animals: From Farms to Zoos to Human Homes." In The Oxford Handbook of Animal Ethics, edited by Tom L. Beauchamp and R. G. Frey, 738-768. New York: Oxford University Press, 2011.

Demello, Margo. "Rabbits in Captivity." In The Ethics of Captivity, edited by Lori Gruen, 77-89. New York: Oxford University Press, 2014.

Dickens, William T. and James R. Flynn. "Heritability Estimates Versus Large Environmental Effects: The IQ Paradox Resolved.” Psychological Review 108, no. 2 (2001): 346-369.

Digiovanna, James. "You Are and Are Not the Person I Once Knew: Eclecticism and Context in Continuity of Identity." Appraisal: A Journal of Constructive and Post Critical Philosophy and Interdisciplinary Studies 9, no.1. (2012): 14-17.

Donaldson, Sue, and Will Kymlicka. Zoopolis: A Political Theory of Animal Rights. New York: Oxford University Press, 2011.

Donovan, Josephine. "Feminism and the Treatment of Animals: From Care to Dialogue." Signs 31, no. 2. (2006): 305-329.

Doyle, Catherine. "Captive Elephants.” In The Ethics of Captivity, edited by Lori Gruen, 38-56. New York: Oxford University Press, 2014.

Düzel, Emrah, Andrew P. Yonelinas, George R. Mangun, Hans-Jochen Heinze, and Endel Tulving. "Event-related Potential Correlates of Two States of Conscious Awareness in Memory." Psychology 94 (1997): 5973-5978.

Epictetus, Discourses 2.9.

Francione, Gary. Animals as Persons: Essays on the Abolition of Animal Exploitation. New York: Columbia University Press, 2008. 
Francione, Gary. Introduction to Animal Rights: Your Child or the Dog? Philadelphia: Temple University Press, 2000.

Francione, Gary, and Robert Garner. The Animal Rights Debate: Abolition or Regulation?. New York: Oxford University Press, 2010.

Galef, Bennett G. "Social Learning and Traditions in Animals: Evidence, Definitions, and Relationship to Human Culture.” Wiley Interdisciplinary Reviews: Cognitive Science 3, no. 6 (2012): 581-529.

Garrett, Aaron. "Animals and Ethics in the History of Modern Philosophy." In The Oxford Handbook of Animal Ethics, edited by Tom L. Beauchamp and R. G. Frey, 61-87. New York: Oxford University Press, 2011.

Gennaro, Rocco. J. "Brute Experience and the Higher-Order Thought Theory of Consciousness." Philosophical Papers 22 (1993): 51-69.

Gennaro, Rocco J. “Animals, Consciousness, and I-thoughts." In The Philosophy of Animal Minds, edited by Robert W. Lurz, 184-200. New York: Cambridge University Press, 2009.

Griffin, Donald R. Animal Minds: Beyond Cognition to Consciousness. Chicago: University of Chicago Press, 2001.

Gruen, Lori. The Ethics of Captivity. New York: Oxford University Press, 2014.

Gruen, Lori. "Dignity, Captivity, and an Ethics of Sight." In The Ethics of Captivity, edited by Lori Gruen, 231-247. New York: Oxford University Press, 2014.

Hunt, Gavin R. "Manufacture and use of hook-tools by New Caledonian crows." Nature 379, no. 6562 (1996): 249-251.

Jamieson, Dale. “Against Zoos.” In In Defense of Animals, edited by Peter Singer, 39- 50. New York: Basil Blackwell, 1985.

Jule, Kristen R., Lisa A. Leaver, and Stephen E.G. Lea. "The Effects of Captive Experience on Reintroduction Survival in Carnivores: A Review and Analysis." Biological Conservation 141 (2008): 355-363.

Kagan, Shelly. "What's Wrong with Speciesism?” Journal of Applied Philosophy 33 (2015): 121 
Kamm, Frances. "Moral Status." In Intricate Ethics: Rights, Responsibilities, and Permissible Harm. New York: Oxford University Press, 2006.

Kant, Immanuel. Critique of Pure Reason. Translated by Norman Kemp Smith. London: Macmillan, 1963.

Kassewitz, Donna. "Games with Dolphins - a Key to Understanding Dolphin Language." Accessed July 14, 2016. http://www.speakdolphin.com/ResearchItems.cfm?ID=12\#donna

Kittay, Eva Feder. “At the Margins of Moral Personhood.” Ethics 116 (2005): 100-131.

Korsgaard, Christine M. "Interacting with Animals: A Kantian Account." In The Oxford Handbook of Animal Ethics, edited by Tom L. Beauchamp and R. G. Frey, 91-118. New York: Oxford University Press, 2011.

Larmer, Robert. "Abortion, Personhood and the Potential for Consciousness." Journal of Applied Philosophy 12, no. 3 (1995): 241-251.

Leopold, Aldo. "The Land Ethic." In A Sand County Almanac and Sketches Here and There. New York: Oxford University Press, 1949.

Marino, Lori. “Cetacean Captivity.” In The Ethics of Captivity, edited by Lori Gruen, 22-37. New York: Oxford University Press, 2014.

Marks, Jonathan. What it Means to be 98\% Chimpanzee: Apes, People, and Their Genes. Los Angeles: University of California Press, 2002.

McAninch, Andrew, Grant Goodrich, and Colin Allen. "Animal Communication and Neoexpressivism." In The Philosophy of Animal Minds, edited by Robert W. Lurz, 128-144. New York: Cambridge University Press, 2009.

McMahan, Jeff. The Ethics of Killing. Oxford: Oxford University Press, 2002.

Midgley, Mary. Beast and Man: The Roots of Human Nature. London: Routledge, 1995.

Morris, Christopher. “The Idea of Moral Standing." In The Oxford Handbook of Animal Ethics, edited by Tom L. Beauchamp and R. G. Frey, 255-275. New York: Oxford University Press, 2011.

Nussbaum, Martha. Aristotle's De Motu Animalium. New York: Princeton University Press, 1986. 
Palmer, Clare. "The Moral Relevance of the Distinction between Domesticated and Wild Animals." In The Oxford Handbook of Animal Ethics, edited by Tom L. Beauchamp and R. G. Frey, 701-725. New York: Oxford University Press, 2011.

Patterson, Francine and Wendy Gordon. "The Case for the Personhood of Gorillas." In The Great Ape Project, edited by Paola Cavelieri and Peter Singer, 58-77. New York: St. Martin's, 1993.

Porphyry. On Abstinence from Killing Animals, trans. Gillian Clark. London: Duckworth, 2000.

Roberts, Robert C. "The Sophistication of Non-human Emotion.” In The Philosophy of Animal Minds, edited by Robert W. Lurz, 218-236. New York: Cambridge University Press, 2009.

Rollin, Bernard E. Animal Rights and Human Morality, $3^{\text {rd }}$ ed. New York: Prometheus Books, 2006.

Ross, Stephen R. "Captive Chimpanzees.” In The Ethics of Captivity, edited by Lori Gruen, 5776. New York: Oxford University Press, 2014.

RT. “Argentine Court Extends Human Right to Freedom to Orangutan.” Accessed March 12, 2015. http://rt.com/news/216551-orangutan-argentina-human-right/

Speak Dolphin. “Dolphin Language Analysis.” Accessed February 19, 2017, http://www.speakdolphin.com/ResearchItems.cfm?ID=14

Singer, Peter. Animal Liberation. New York: HarperCollins, 1975.

Singer, Peter. Practical Ethics. New York: Cambridge University Press, 1979.

Tooley, Michael. “Are Nonhuman Animals Persons?” In The Oxford Handbook of Animal Ethics, edited by Tom L. Beauchamp and R. G. Frey, 332-370. New York: Oxford University Press, 2011.

Warren, Mary Anne. "On the Moral and Legal Status of Abortion.” The Monist 57, no. 4 (1973): 1-9. 